Supplemental Information for

\title{
Elucidation of a copper binding site in proinsulin C-peptide and its implications on metal- modulated activity
}

Michael J. Stevenson, Samuel E. Janisse, Lizhi Tao, Ryan L. Neil, Quang D. Pham, R. David Britt, Marie C. Heffern*

Department of Chemistry, University of California, Davis, Davis, CA 95616

*Corresponding author: mcheffern@ucdavis.edu

Table of Contents

Figure S1. NMR spectra of metal competition for C-peptide 1

Figure S2. NMR spectra of C-peptide with sub-stoichiometric addition of $\mathrm{Cu}(\mathrm{II}) \quad 2$

Figure S3. $\quad{ }^{1} \mathrm{H}-{ }^{1} \mathrm{H}$ TOCSY and NOESY spectra of C-peptide 3

Figure S4. $\quad \Delta \delta$ plots of $\mathrm{NH}$ and $\mathrm{CH} \alpha$ for $\mathrm{Zn}(\mathrm{II}) / \mathrm{C}$-peptide and $\mathrm{Cu}(\mathrm{II}) / \mathrm{C}$-peptide 4

Figure S5. $\quad \Delta \delta$ plots of side chains for $\mathrm{Zn}(\mathrm{II}) / \mathrm{C}$-peptide and $\mathrm{Cu}(\mathrm{II}) / \mathrm{C}$-peptide $\quad 5$

Figure S6. Second derivative of FTIR spectra for apo and $\mathrm{Cu}(\mathrm{II}) / \mathrm{C}$-peptide 6

Figure S7. Representative thermogram of $\mathrm{Cu}$ (II) titrated into C-peptide (MOPSO) 7

Figure S8. Analysis to determine proton displacement on C-peptide 8

Figure S9. Representative thermograms of Zn(II) titrated into C-peptide 9

Figure S10. First derivatives of UV-Vis spectra of $\mathrm{Cu}$ (II)-bound C-peptide variants 10

Figure S11. $\Delta \delta$ plots of $\mathrm{NH}$ and $\mathrm{CH} \alpha$ for metal-bound E3A/D4A C-peptide 11

Figure S12. $\Delta \delta$ plots of side chains for metal-bound E3A/D4A C-peptide $\quad 12$

Figure S13. Representative thermograms of $\mathrm{Cu}$ (II) titrated into E3A/D4A C-peptide 13

Figure S14. $\quad$ CW EPR spectra of $\mathrm{Cu}(\mathrm{II})$-bound C-peptide, N-term, and C-term 14

Figure S15. HYSCORE spectra of Cu(II)-bound C-peptide, N-term, and C-term 15

Figure S16. $\quad{ }^{1} \mathrm{H}$ NMR spectra of apo and $\mathrm{Cu}(\mathrm{II}) / \mathrm{N}$-term $\quad 16$

$\begin{array}{lll}\text { Figure S17. } & { }^{1} \mathrm{H} \text { NMR spectra of apo and } \mathrm{Cu}(\mathrm{II}) / \mathrm{C} \text {-term } & 17\end{array}$

Figure S18. Representative thermograms of $\mathrm{Cu}$ (II) titrated into N-term and C-term 18

Table S1. Chemical shifts of ${ }^{1} \mathrm{H}$ resonances of apo C-peptide $\quad 19$

Table S2. Chemical shifts of ${ }^{1} \mathrm{H}$ resonances of $\mathrm{Zn}$ (II)/C-peptide 20

Table S3. Chemical shifts of ${ }^{1} \mathrm{H}$ resonances of $\mathrm{Cu}(\mathrm{II}) / \mathrm{C}$-peptide 21

Table S4. $\quad \Delta \delta$ of assigned ${ }^{1} \mathrm{H}$ resonances of $\mathrm{Zn}(\mathrm{II}) / \mathrm{C}$-peptide and apo C-peptide $\quad 22$

Table S5. $\quad \Delta \delta$ of assigned ${ }^{1} \mathrm{H}$ resonances of $\mathrm{Cu}(\mathrm{II}) / \mathrm{C}$-peptide and apo C-peptide $\quad 23$

Table S6. ITC experimental fit parameters 24

Table S7. Chemical shifts of ${ }^{1} \mathrm{H}$ resonances of apo E3A/D4A C-peptide 25

Table S8. Chemical shifts of ${ }^{1} \mathrm{H}$ resonances of $\mathrm{Cu}$ (II)-bound E3A/D4A C-peptide 26

Table S9. $\quad \Delta \delta$ of assigned ${ }^{1} \mathrm{H}$ resonances of $\mathrm{Cu}(\mathrm{II})$ and apo E3A/D4A C-peptide 27

Table S10. ITC fit and buffer-independent parameters for C-peptide variants 28

Scheme S1. Determination of $\Delta \mathrm{H}_{\mathrm{Cu}(\mathrm{II}) \text {-MOpso }} \quad 29$

References $\quad 30$ 


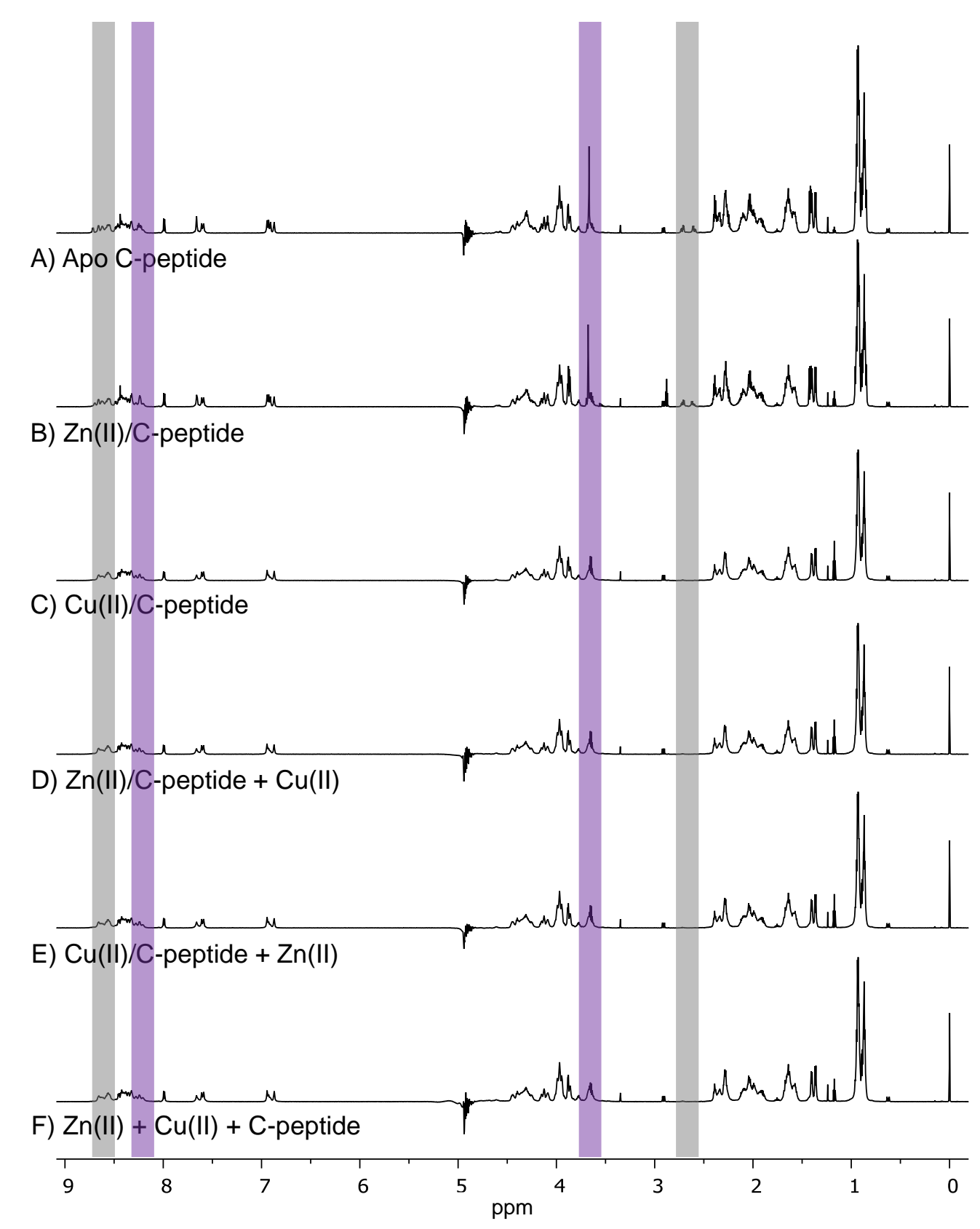

Figure S1. ${ }^{1} \mathrm{H}$ NMR spectra of A) apo C-peptide, B) Zn(II)/C-peptide, C) $\mathrm{Cu}$ (II)/C-peptide, D) equimolar $\mathrm{Cu}$ (II) added to $\mathrm{Zn}$ (II)/C-peptide, E) equimolar $\mathrm{Zn}$ (II) added to $\mathrm{Cu}$ (II)/C-peptide, and F) $\mathrm{Cu}(\mathrm{II})$ and $\mathrm{Zn}$ (II) added to apo C-peptide simultaneously. Grey highlighted regions of spectra are enlarged and shown in Figure 3 and are due to $\mathrm{CH} \beta$ protons on D4 (2.7 ppm) and backbone amide protons from E3 $(8.7 \mathrm{ppm})$. Purple highlighted regions of the spectra are due to glycine protons $(3.7 \mathrm{ppm})$ and the backbone amide proton from L5 $(8.2 \mathrm{ppm})$. All spectra were collected at $800 \mathrm{MHz}$ in $95: 5 \mathrm{H}_{2} \mathrm{O}: \mathrm{D}_{2} \mathrm{O}$ and $10 \mathrm{mM}$ Tris- $\mathrm{d}_{11}$, $\mathrm{pH} 7.4$ at $10{ }^{\circ} \mathrm{C}$. Addition of $\mathrm{Zn}$ (II) induces shifts in proton resonances while $\mathrm{Cu}(\mathrm{II})$ obliterates proton resonances within these regions. The spectra of $\mathrm{Cu}(\mathrm{II})$ competition with $\mathrm{Zn}$ (II) (D, E, and F) result in spectra that resemble $\mathrm{Cu}(\mathrm{II}) / \mathrm{C}$ peptide and not $\mathrm{Zn}(\mathrm{II}) / \mathrm{C}$-peptide indicating that $\mathrm{Cu}$ (II) displaces $\mathrm{Zn}$ (II) for binding $\mathrm{C}$-peptide. 

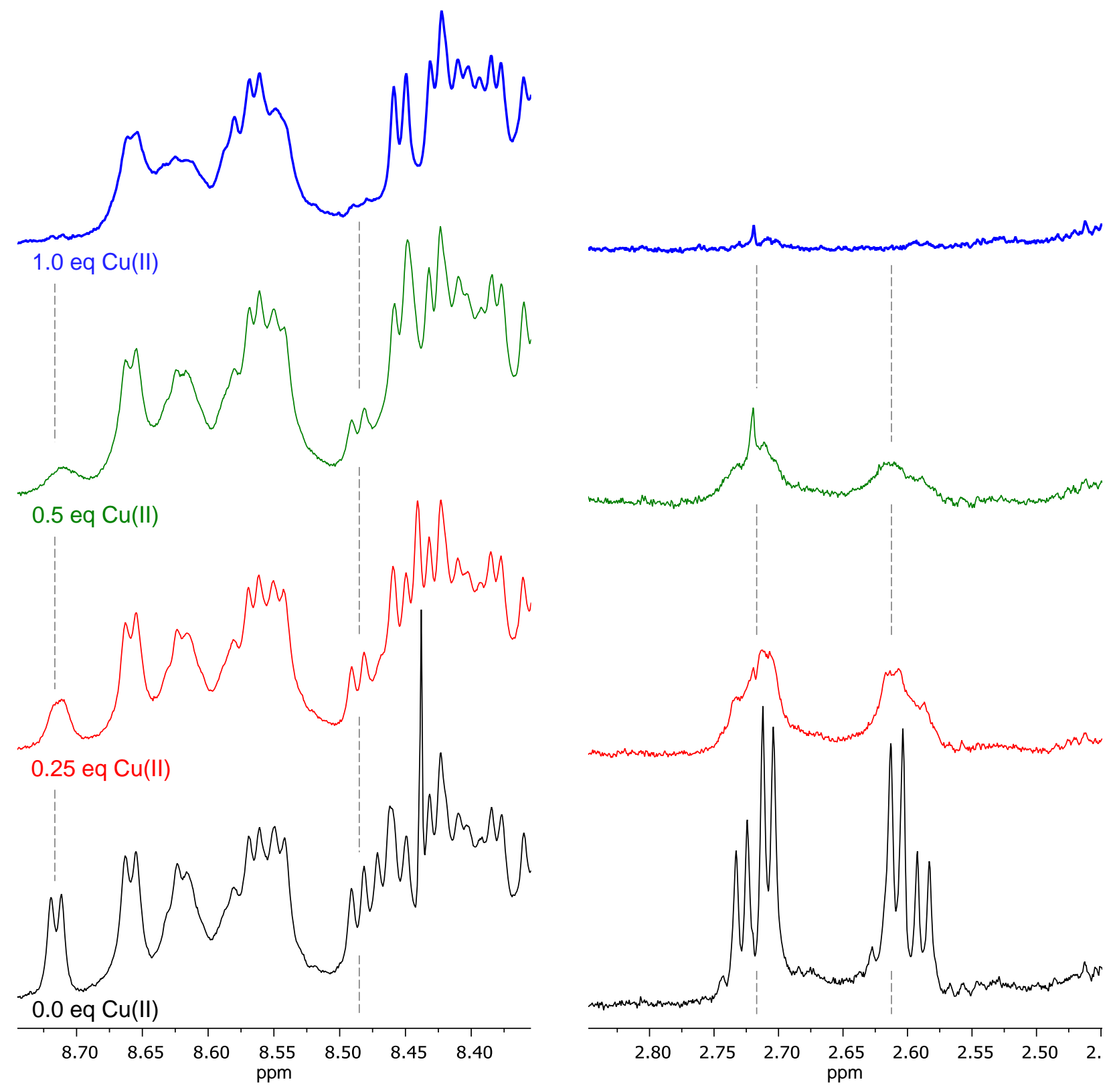

Figure S2. NMR spectra of $250 \mu \mathrm{M}$ apo C-peptide (black) and $250 \mu \mathrm{M}$ C-peptide with $62.5 \mu \mathrm{M}$ (red), $125 \mu \mathrm{M}$ (green), and $250 \mu \mathrm{M}$ (blue) $\mathrm{Cu}(\mathrm{II}) . \mathrm{Cu}(\mathrm{II})$ obliterates the proton resonances of $\mathrm{CH} \beta$ protons on D4 (2.6 ppm) and backbone amide protons from D4 (8.45 ppm) and E3 (8.7 ppm) (dashed lines). Solutions were prepared in 95:5 (v/v) H2O:D2O with $10 \mathrm{mM}$ Tris-d11 at pH 7.4 and spectra were collected at $800 \mathrm{MHz}$ and $10{ }^{\circ} \mathrm{C}$. 

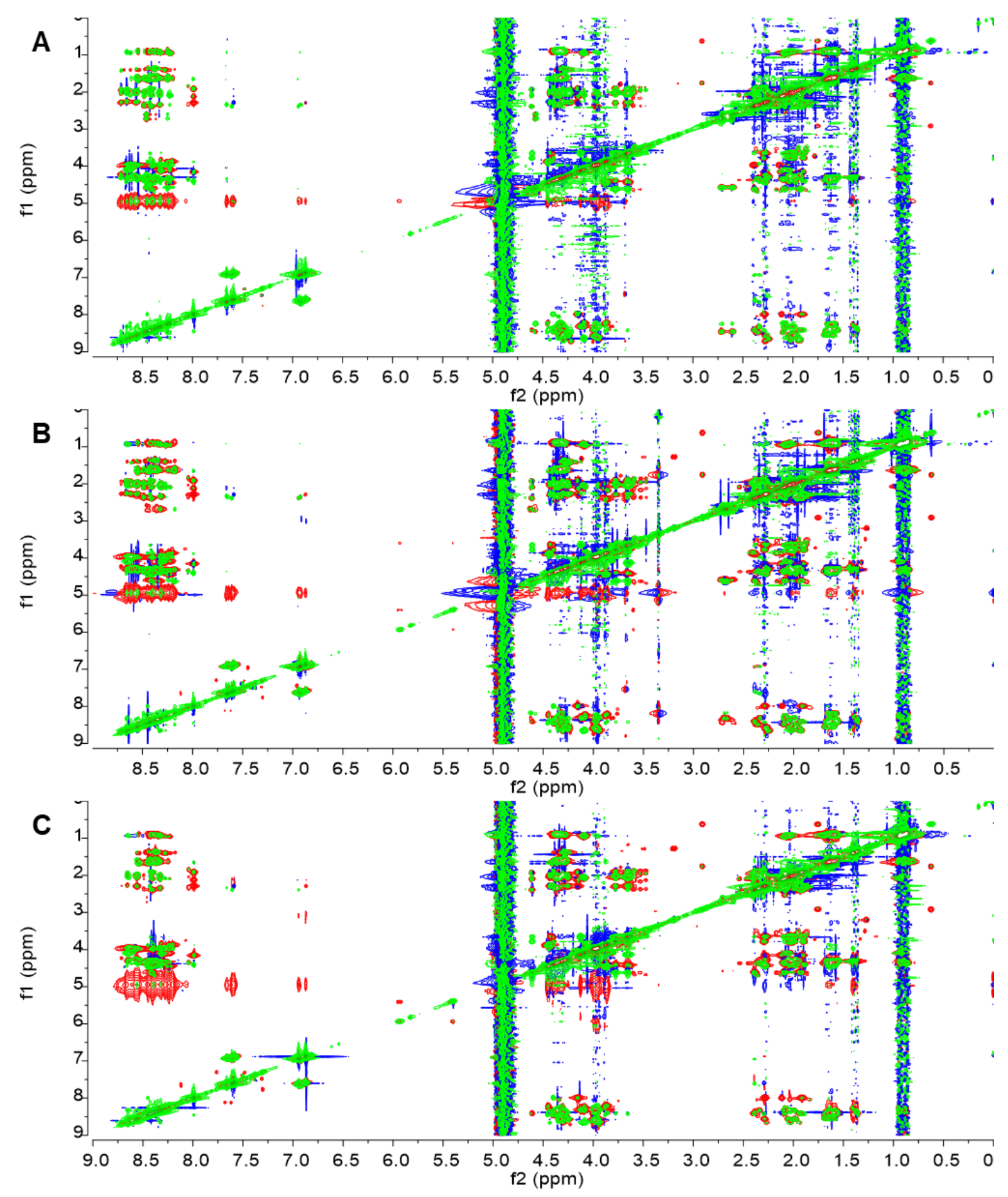

Figure S3. Overlay of full ${ }^{1} \mathrm{H}-{ }^{1} \mathrm{H}$ TOCSY (red-blue) and ${ }^{1} \mathrm{H}-{ }^{1} \mathrm{H}$ NOESY (green-blue) spectra for $1.5 \mathrm{mM} \mathrm{A}$ ) apo C-peptide, B) $\mathrm{Zn}(\mathrm{II}) / \mathrm{C}$-peptide, and C) $\mathrm{Cu}(\mathrm{II}) / \mathrm{C}$-peptide. All spectra were collected at $800 \mathrm{MHz}$ in 95:5 $\mathrm{H}_{2} \mathrm{O}: \mathrm{D}_{2} \mathrm{O}$ and $10 \mathrm{mM}$ Tris- $\mathrm{d}_{11}, \mathrm{pH} 7.4$ at $10{ }^{\circ} \mathrm{C}$. 

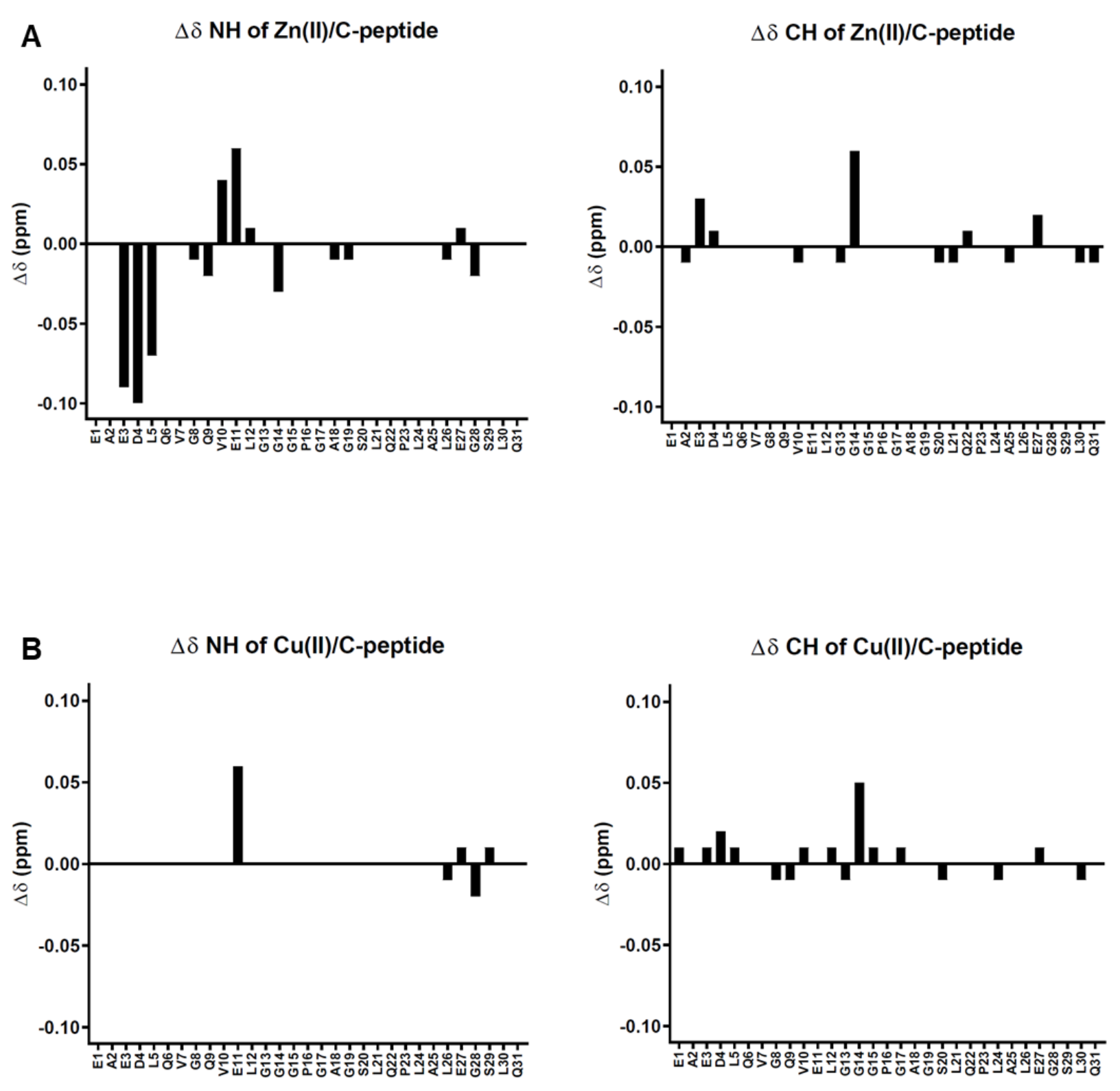

Figure S4. The $\Delta \delta\left(\delta\left(\mathrm{M}^{2+} / \mathrm{C}\right.\right.$-peptide $)-\delta$ (apo C-peptide $\left.)\right)$ of ${ }^{1} \mathrm{H}$ chemical shifts (ppm) of the backbone amide $(\mathrm{NH})$ and $\mathrm{CH} \alpha$ protons plotted against C-peptide sequence for $\mathrm{A}$ ) $\mathrm{Zn}(\mathrm{II}) / \mathrm{C}$ peptide and B) $\mathrm{Cu}(\mathrm{II}) / \mathrm{C}$-peptide. $\Delta \delta$ plots for the backbone side chain protons are shown in Figure S5. Solutions were prepared at $1.5 \mathrm{mM}$ peptide in 95:5 (v/v) $\mathrm{H}_{2} \mathrm{O}: \mathrm{D}_{2} \mathrm{O}$ with $10 \mathrm{mM}$ Tris- $\mathrm{d}_{11}$ at $\mathrm{pH}$ 7.4 and spectra were collected at $800 \mathrm{MHz}$ and $10{ }^{\circ} \mathrm{C}$. The $\Delta \delta$ of $\mathrm{NH}$ for E3, D4, L5, V10, and E11 show significant effects on the ${ }^{1} \mathrm{H}$ resonances compared with other $\mathrm{NH}$ protons and indicate a possible location of metal binding. ${ }^{1} \mathrm{H}$ chemical shift assignments are tabulated in Table S1-S5. 


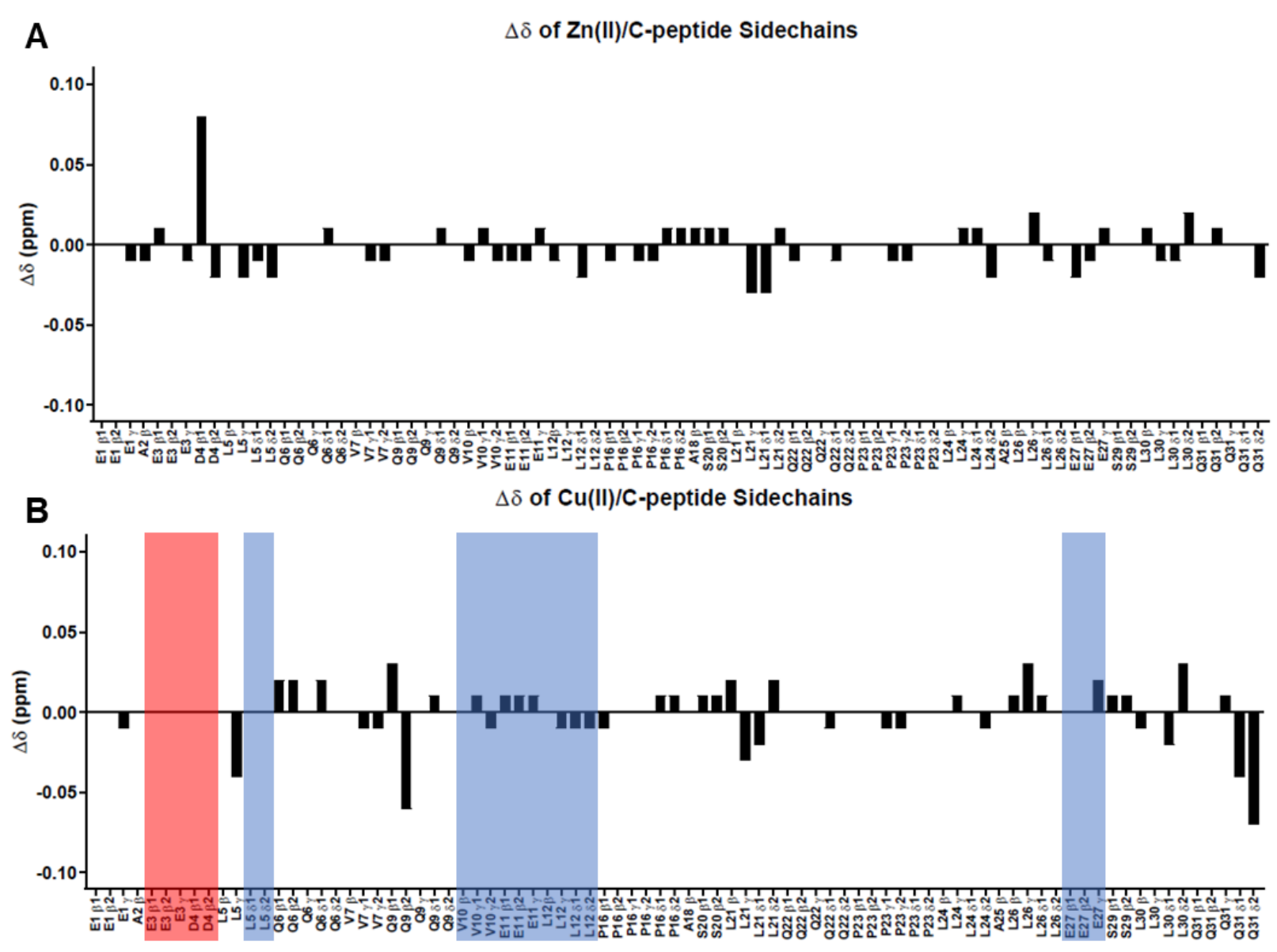

Figure S5. The $\Delta \delta\left(\delta\left(\mathrm{M}^{2+} / \mathrm{C}\right.\right.$-peptide $)-\delta$ (apo WT C-peptide) $)$ of ${ }^{1} \mathrm{H}$ chemical shifts (ppm) of amino acid side chains plotted against WT C-peptide sequence for A) $\mathrm{Zn}$ (II)/C-peptide and B) $\mathrm{Cu}(\mathrm{II}) / \mathrm{C}$-peptide. $\Delta \delta$ plots for the backbone amide and $\mathrm{CH} \alpha$ protons are shown in Figure $\mathrm{S} 4$. Solutions were prepared at $1.5 \mathrm{mM}$ peptide in 95:5 (v/v) $\mathrm{H}_{2} \mathrm{O}: \mathrm{D}_{2} \mathrm{O}$ with $10 \mathrm{mM}$ Tris- $\mathrm{d}_{11}$ at $\mathrm{pH} 7.4$ and spectra were collected at $800 \mathrm{MHz}$ and $10{ }^{\circ} \mathrm{C}$. The proton resonances with shading indicate reduced (blue) or obliterated (red) intensities. Coordination by $\mathrm{Zn}$ (II) on D4 and by $\mathrm{Cu}$ (II) on E3 and D4 show significant effects on the ${ }^{1} \mathrm{H}$ resonances compared with other amino acid protons and indicate location of metal binding. ${ }^{1} \mathrm{H}$ chemical shift assignments are tabulated in Tables S1-S5. 


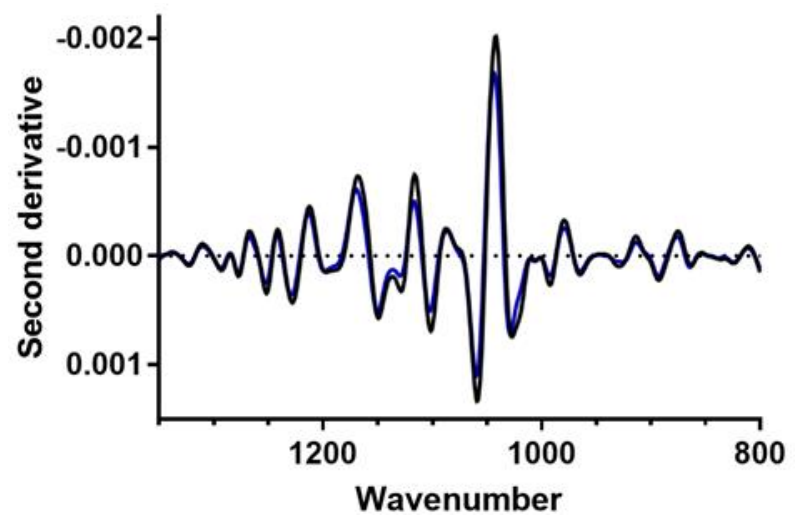

Figure S6. Second derivative FTIR spectra of WT C-peptide (black) and $\mathrm{Cu}(\mathrm{II}) / \mathrm{C}$-peptide (blue) at low wavenumbers. The second derivative patterns between apo and $\mathrm{Cu}$ (II)-bound peptides are similar in this region indicating that the stretching and bending frequencies of serine are not affected by $\mathrm{Cu}(\mathrm{II})$. 


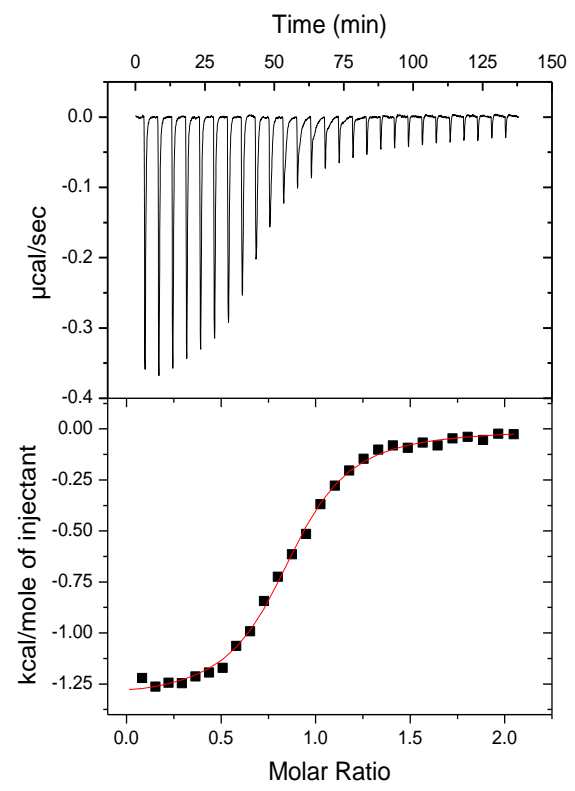

Figure S7. Representative thermogram of $1.0 \mathrm{mM} \mathrm{Cu}$ (II) titrated into $100 \mu \mathrm{M}$ C-peptide in 15 mM MOPSO, $\mathrm{pH} 7.4$ with red fit line: $\mathrm{n}=0.852 \pm 0.006 ; \mathrm{K}_{\mathrm{ITC}}=3.0( \pm 0.2) \times 10^{5} ; \Delta \mathrm{H}_{\mathrm{ITC}}=-1.33$ $\pm 0.01 \mathrm{kcal} \mathrm{mol}^{-1}$. Buffer-independent thermodynamics are summarized in Table 2 and indicate a predominantly entropic driving force. 


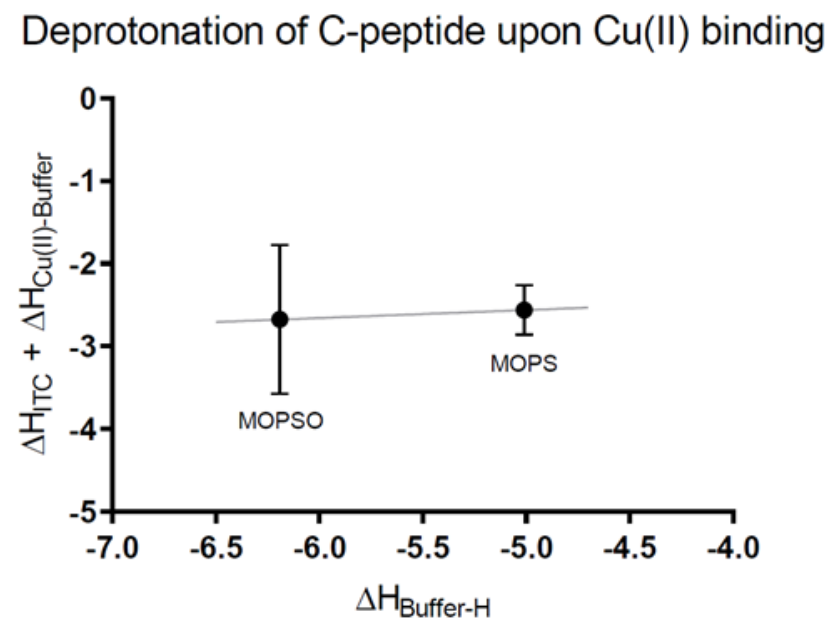

Figure S8. Analysis to determine the number of protons that are displaced from C-peptide upon

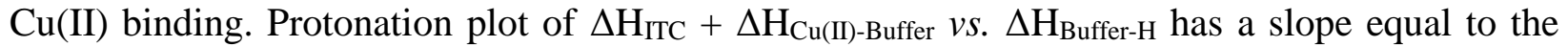
number of protons as detailed by Grossoehme et al. ${ }^{1}$ that are binding to the buffer and is equal to $0.1 \pm 0.2$. The error of the slope is estimated from subtraction of the minimum slope from the maximum slope between the error bars divided by two. 

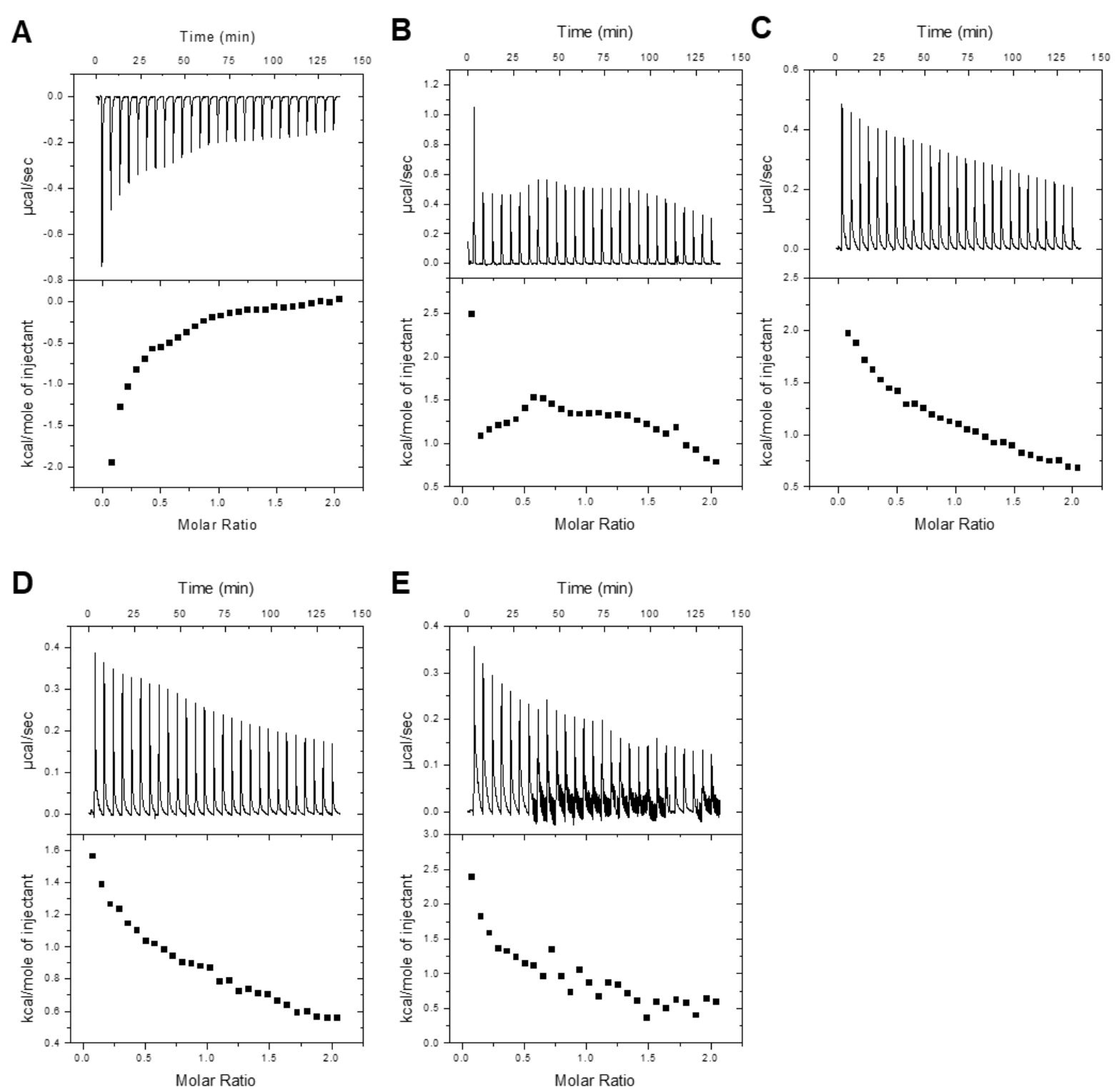

Figure S9. Representative thermograms of $1.0 \mathrm{mM} \mathrm{Zn(II)} \mathrm{titrated} \mathrm{into} 100 \mu \mathrm{M}$ C-peptide in A) 15 $\mathrm{mM}$ Tris, pH 7.4, B) $15 \mathrm{mM}$ bisTris, pH 7.4, C) $15 \mathrm{mM}$ MOPS, pH 7.4, D) $15 \mathrm{mM}$ MOPSO, pH 7.4, and E) $15 \mathrm{mM}$ PIPES, pH 7.4. The titrations were inconsistent, do not indicate specific $\mathrm{Zn}$ (II)binding, and are most likely from heat of dilution from the $\mathrm{Zn}$ (II) titration into the cell. 


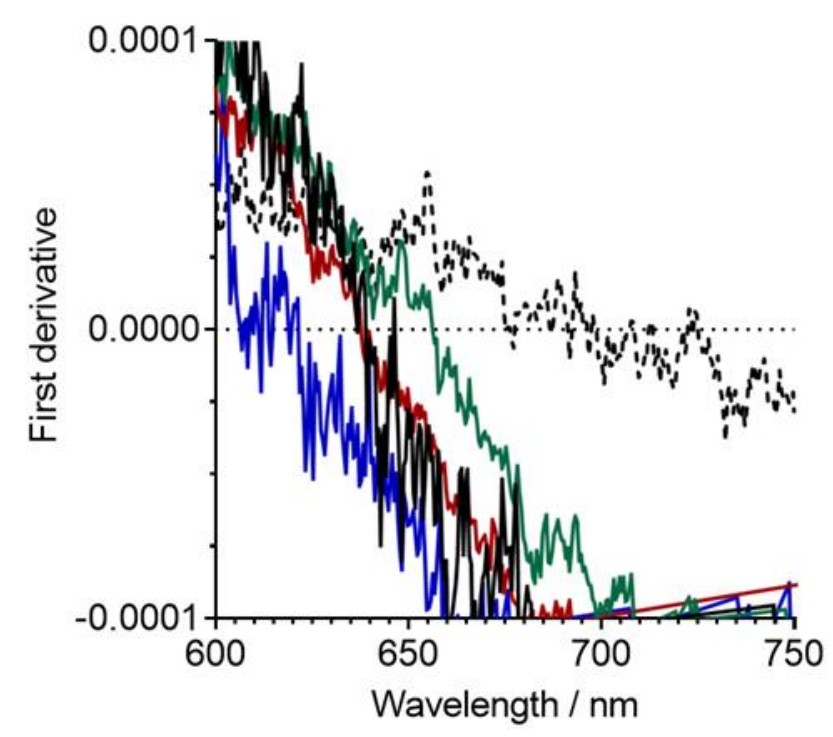

Figure S10. First derivatives of the spectra shown in Figure 7 corresponding to WT C-peptide (black), E3A C-peptide (red), D4A C-peptide (blue), E3A D4A C-peptide (green), and Cu(II) in $15 \mathrm{mM}$ MOPS, $\mathrm{pH} 7.4$ (black, dashed). $\lambda_{\max }$ for the d-d band as determined by the first derivative of WT, E3A, D4A, E3A D4A C-peptide, and Cu(II) in buffer are 638, 637, 620, 658, and $696 \mathrm{~nm}$, respectively. Derivatives of spectra were processed by a 20-point smoothing. The similar energy of the $\mathrm{d}$-d band from $\mathrm{Cu}$ (II) suggests that the $\mathrm{Cu}$ (II) is bound to similar ligands in all peptides. The $\lambda_{\max }$ of E3A D4A C-peptide is red-shifted, is most similar to buffer alone, and exhibits the largest change in $\lambda_{\max }$ among the mutants relative to WT C-peptide. 


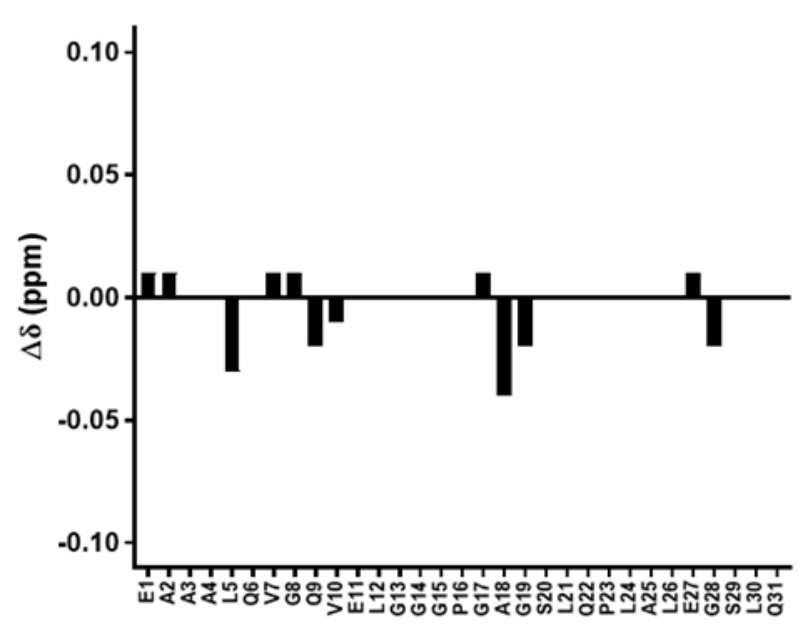

B $\Delta \delta \mathrm{CH}$ of $\mathrm{Cu}(\mathrm{II}) / \mathrm{E} 3 \mathrm{~A}$ D4A C-peptide

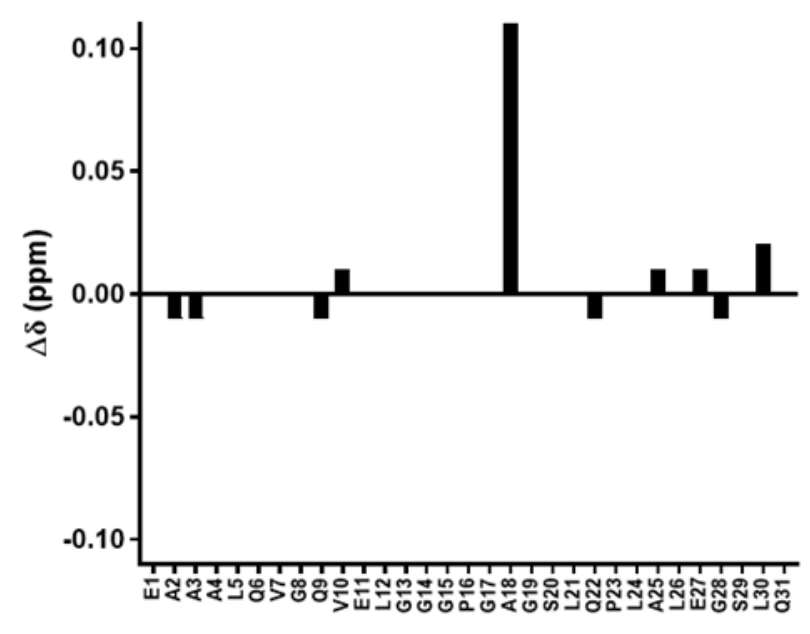

Figure S11. The $\Delta \delta\left(\delta(\mathrm{Cu}(\mathrm{II}) / \mathrm{E} 3 \mathrm{~A}\right.$ D4A C-peptide) $-\delta$ (apo E3A D4A C-peptide) $)$ of ${ }^{1} \mathrm{H}$ chemical shifts (ppm) of the A) backbone amide ( $\mathrm{NH})$ and $\mathrm{B}) \mathrm{CH} \alpha$ protons plotted against peptide sequence. Solutions were prepared at $1.5 \mathrm{mM}$ peptide in 95:5 (v/v) $\mathrm{H}_{2} \mathrm{O}: \mathrm{D}_{2} \mathrm{O}$ with $10 \mathrm{mM}$ Tris- $\mathrm{d}_{11}$ at $\mathrm{pH} 7.4$ and spectra were collected at $800 \mathrm{MHz}$ and $10{ }^{\circ} \mathrm{C} . \Delta \delta$ plots for the backbone side chain protons are shown in Figure $\mathrm{S} 12$. The small $\Delta \delta$ indicate minimal changes in peptide structure upon $\mathrm{Cu}(\mathrm{II})$ binding. ${ }^{1} \mathrm{H}$ chemical shift assignments are tabulated in Tables S7-S9. 


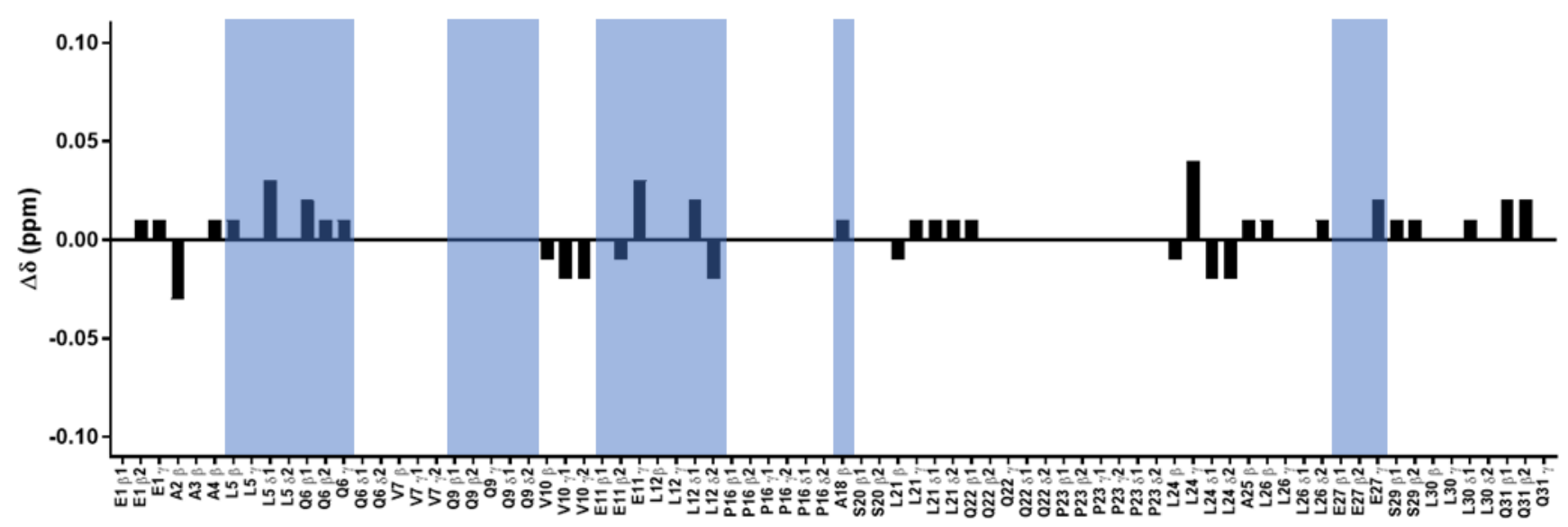

Figure S12. The $\Delta \delta\left(\delta(\mathrm{Cu}(\mathrm{II}) / \mathrm{E} 3 \mathrm{~A}\right.$ D4A C-peptide) $-\delta$ (apo E3A D4A C-peptide) $)$ of ${ }^{1} \mathrm{H}$ chemical shifts (ppm) of amino acid side chains plotted against peptide sequence. Solutions were prepared at $1.5 \mathrm{mM}$ peptide in $95: 5(\mathrm{v} / \mathrm{v}) \mathrm{H}_{2} \mathrm{O}: \mathrm{D}_{2} \mathrm{O}$ with $10 \mathrm{mM}$ Tris- $\mathrm{d}_{11}$ at $\mathrm{pH} 7.4$ and spectra were collected at $800 \mathrm{MHz}$ and $10{ }^{\circ} \mathrm{C} . \Delta \delta$ plots for the backbone amide and $\mathrm{CH} \alpha$ protons are in the Figure S11. The proton resonances with shading indicate reduced (blue) intensities. Mutation of the $\mathrm{Cu}$ (II) binding site (E3 and D4) to alanines shifts $\mathrm{Cu}(\mathrm{II})$-binding to other residues (Q6, E11, and E27) that also had reduced intensities in WT and indicate multiple modes of $\mathrm{Cu}(\mathrm{II})$ binding where the preferential is E3 and D4. ${ }^{1} \mathrm{H}$ chemical shift assignments are tabulated in Tables S7-S9. 
A

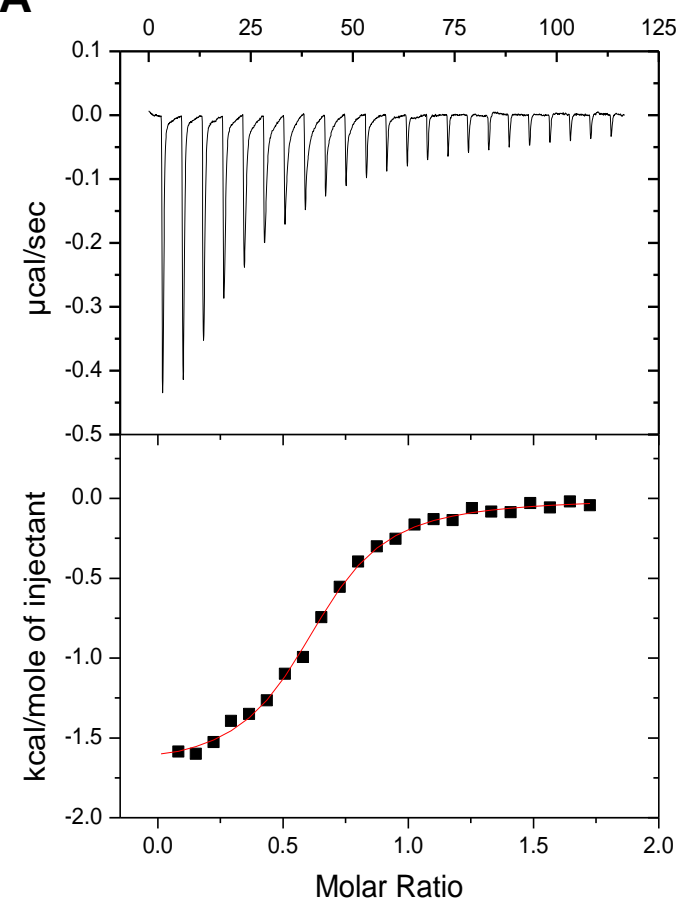

B
Deprotonation of E3A/D4A C-peptide upon $\mathrm{Cu}(\mathrm{II})$ binding

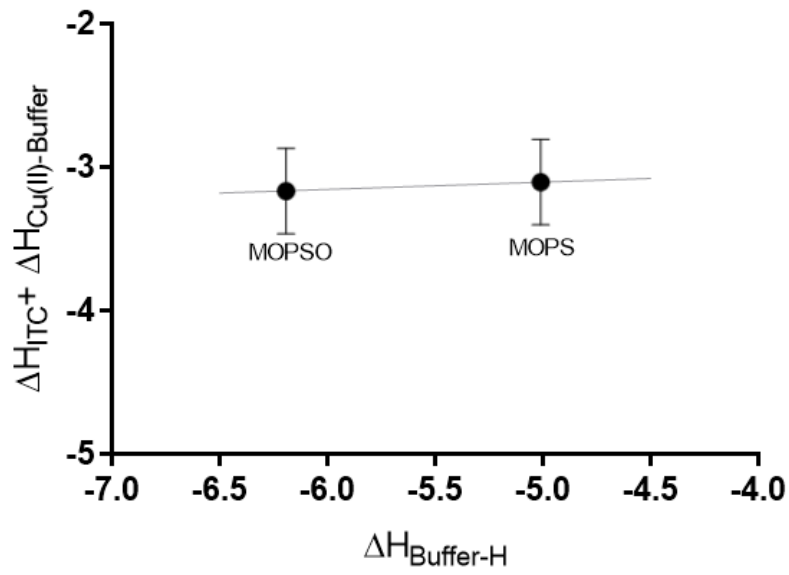

Figure S13. A) Representative thermogram of $1.0 \mathrm{mM} \mathrm{Cu}(\mathrm{II})$ titrated into $100 \mu \mathrm{M}$ E3A/D4A Cpeptide in $15 \mathrm{mM}$ MOPSO, $\mathrm{pH} 7.4$ with red fit line: $\mathrm{n}=0.621 \pm 0.006 ; \mathrm{K}_{\text {ITC }}=2.6( \pm 0.2) \times 10^{5}$; $\Delta \mathrm{H}_{\text {ITC }}=-1.70 \pm 0.02 \mathrm{kcal} \mathrm{mol}^{-1}$. B) Protonation plot of $\Delta \mathrm{H}_{\text {ITC }}+\Delta \mathrm{H}_{\mathrm{Cu}(\mathrm{II}) \text {-Buffer }} v s . \Delta \mathrm{H}_{\text {Buffer-H has a }}$ slope equal to the number of protons as detailed by Grossoehme et al. ${ }^{1}$ that are binding to the buffer and is equal to $0.1 \pm 0.6$. The large error of the slope is estimated from subtraction of the minimum slope from the maximum slope between the error bars divided by two. Bufferindependent thermodynamics are summarized in Table S10 and indicate a predominantly entropic driving force. 


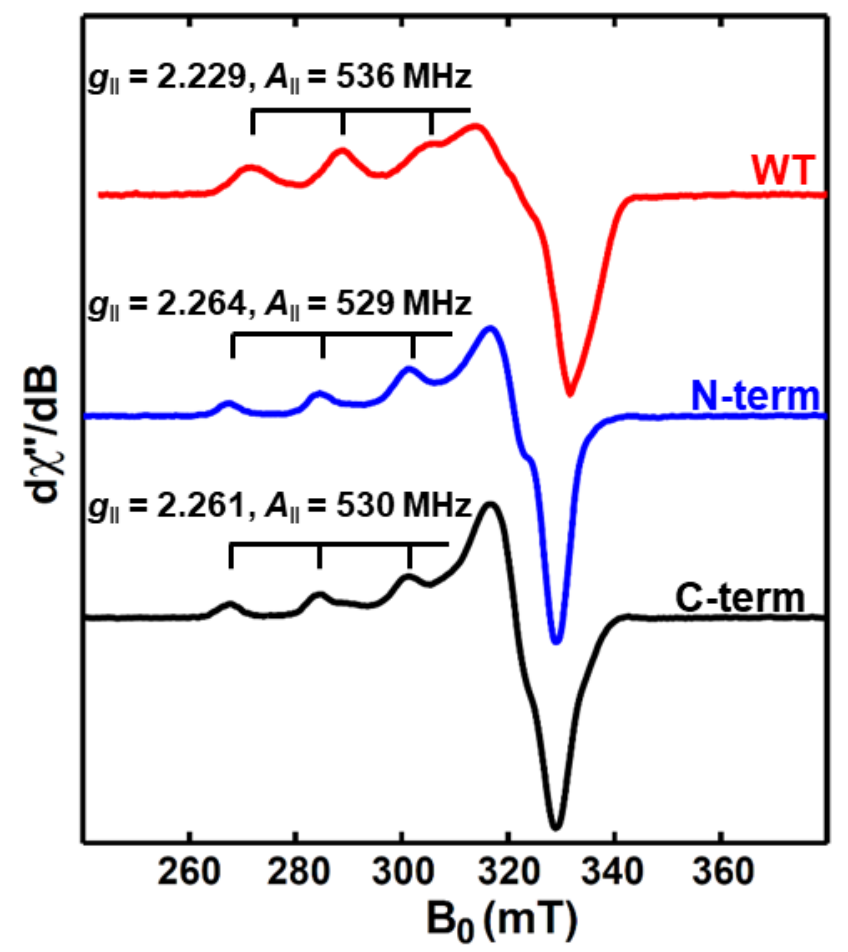

Figure S14. X-band EPR of $\mathrm{Cu}(\mathrm{II})$ bound to WT C-peptide (red), N-term (blue), and C-term (black) and collected at $20 \mathrm{~K}$. WT C-peptide from Figure 5 is shown here for clarity of comparisons to truncations. Samples were prepared with $0.5 \mathrm{mM} \mathrm{Cu}(\mathrm{II})$ and $1.0 \mathrm{mM} \mathrm{C}$-peptide in $15 \mathrm{mM}$ MOPS, pH 7.4 with $20 \%$ ethylene glycol as a glassing agent. These spectra indicate that $\mathrm{Cu}(\mathrm{II})$ is bound in a square planar geometry to either $4 \mathrm{O}$ or $3 \mathrm{O} 1 \mathrm{~N}$ coordination. ${ }^{2}$ 
A

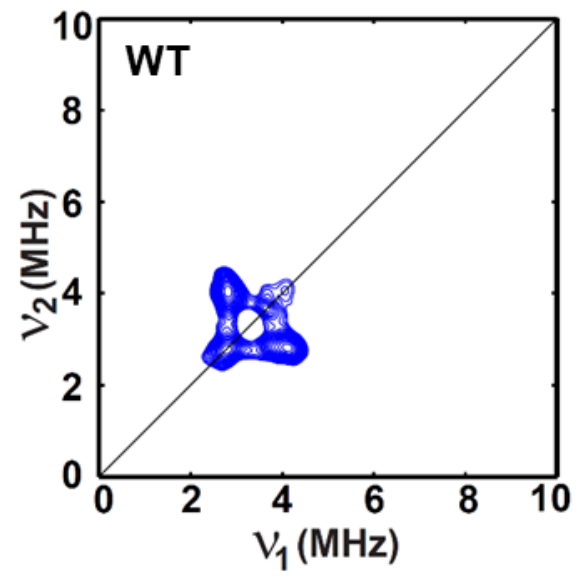

B

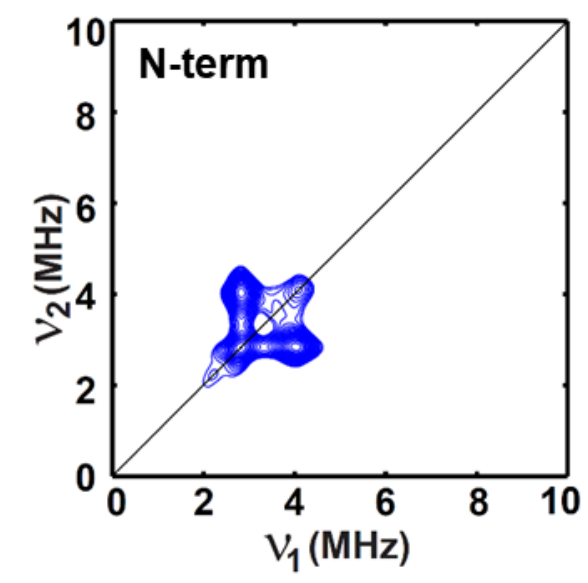

C

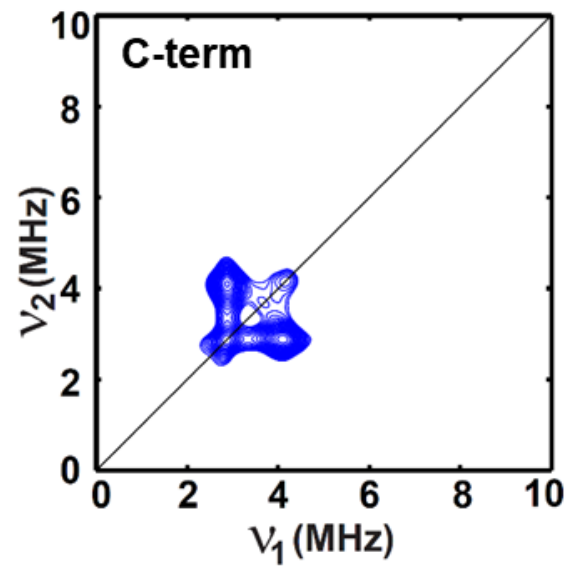

Figure S15. HYSCORE spectra of Cu(II) bound to A) WT C-peptide, B) N-term, and C) C-term and collected at $20 \mathrm{~K}$. WT C-peptide from Figure 5 is shown here for clarity of comparisons to truncations. 

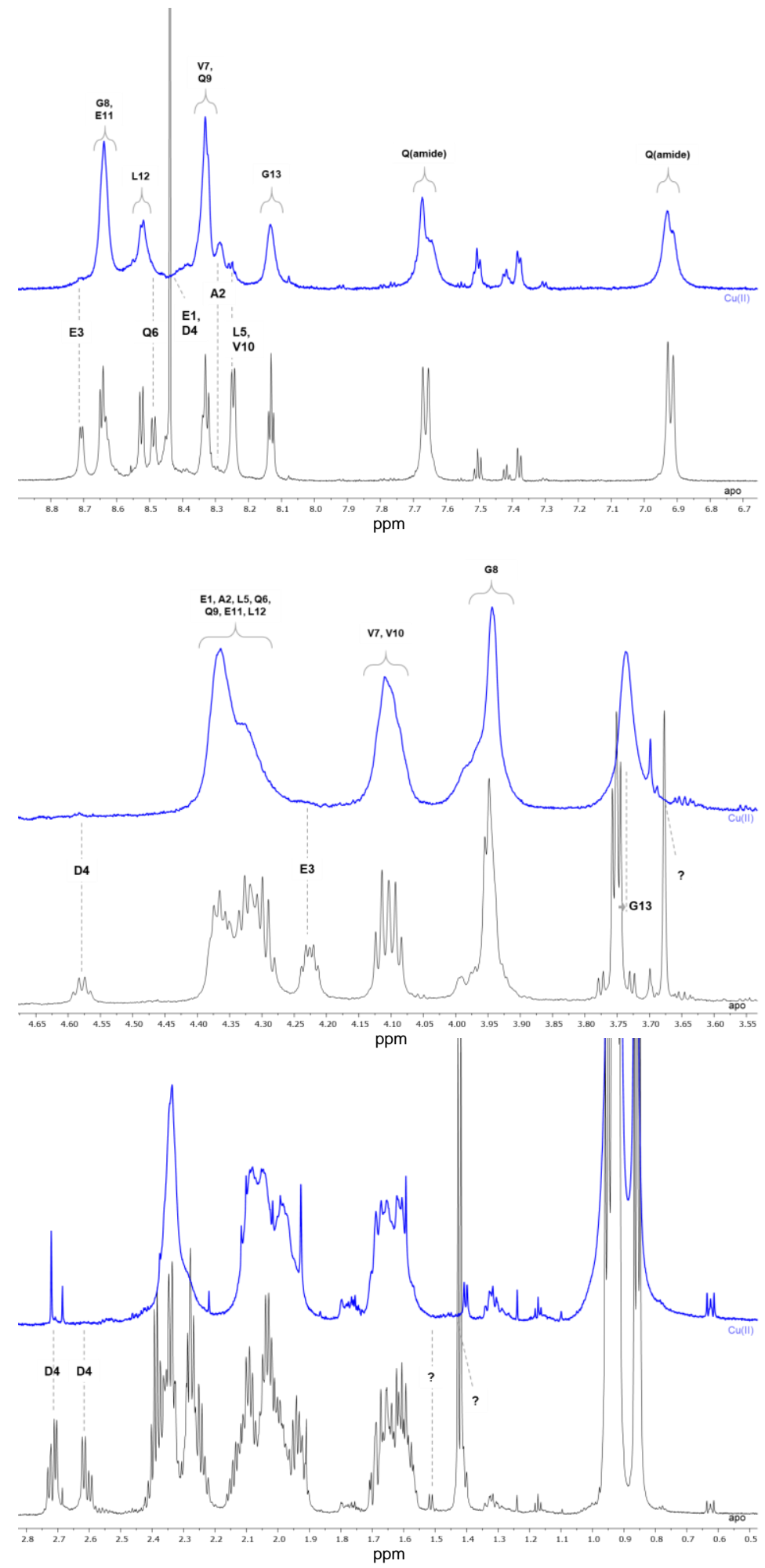

Figure S16. NMR spectra of apo and $\mathrm{Cu}$ (II) bound $\mathrm{N}$-term $\mathrm{C}$-peptide with assigned peaks and noted differences when $\mathrm{Cu}$ (II) is bound. Solutions were prepared at $1.5 \mathrm{mM}$ peptide in 95:5 (v/v) $\mathrm{H}_{2} \mathrm{O}: \mathrm{D}_{2} \mathrm{O}$ with $10 \mathrm{mM}$ Tris- $\mathrm{d}_{11}$ at $\mathrm{pH} 7.4$ and spectra were collected at $800 \mathrm{MHz}$ and $10{ }^{\circ} \mathrm{C}$. 

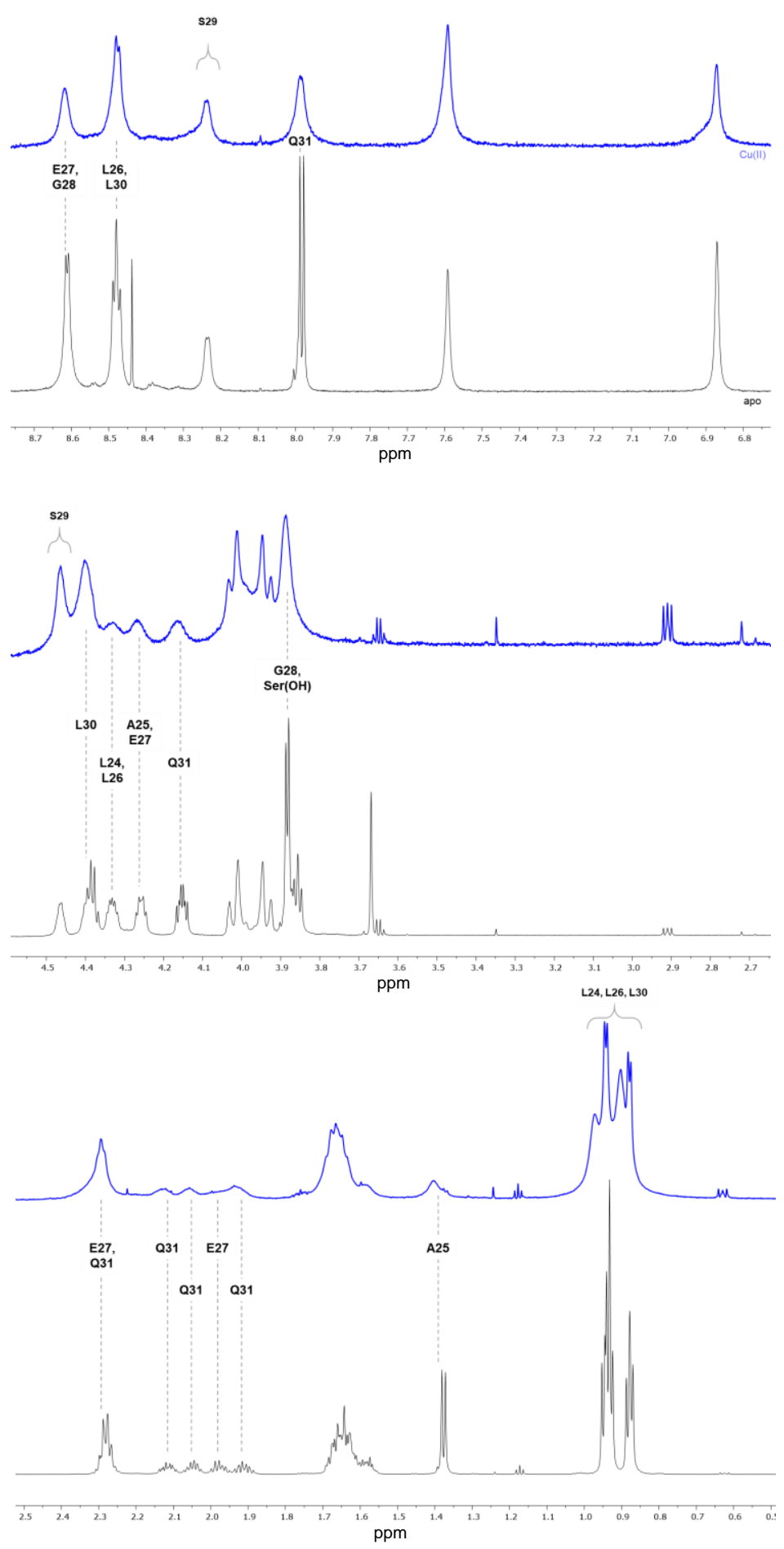

Figure S17. NMR spectra of apo and $\mathrm{Cu}(\mathrm{II})$ bound $\mathrm{C}$-term $\mathrm{C}$-peptide with assigned peaks and noted differences when $\mathrm{Cu}(\mathrm{II})$ is bound. Solutions were prepared at $1.5 \mathrm{mM}$ peptide in 95:5 (v/v) $\mathrm{H}_{2} \mathrm{O}: \mathrm{D}_{2} \mathrm{O}$ with $10 \mathrm{mM}$ Tris-d $\mathrm{d}_{11}$ at $\mathrm{pH} 7.4$ and spectra were collected at $10{ }^{\circ} \mathrm{C}$. 
A

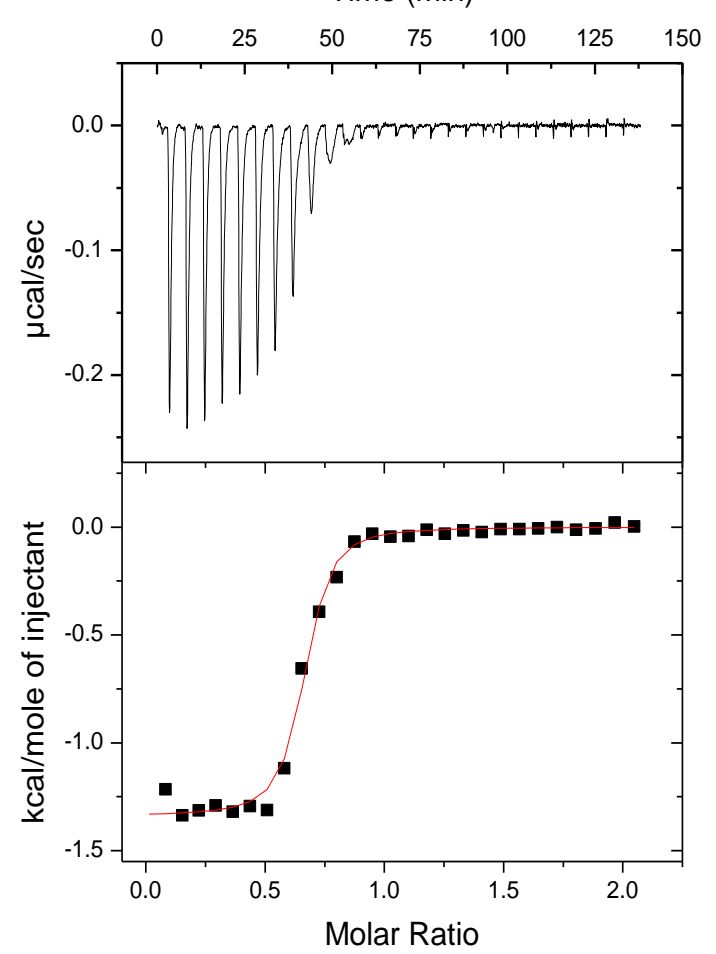

B

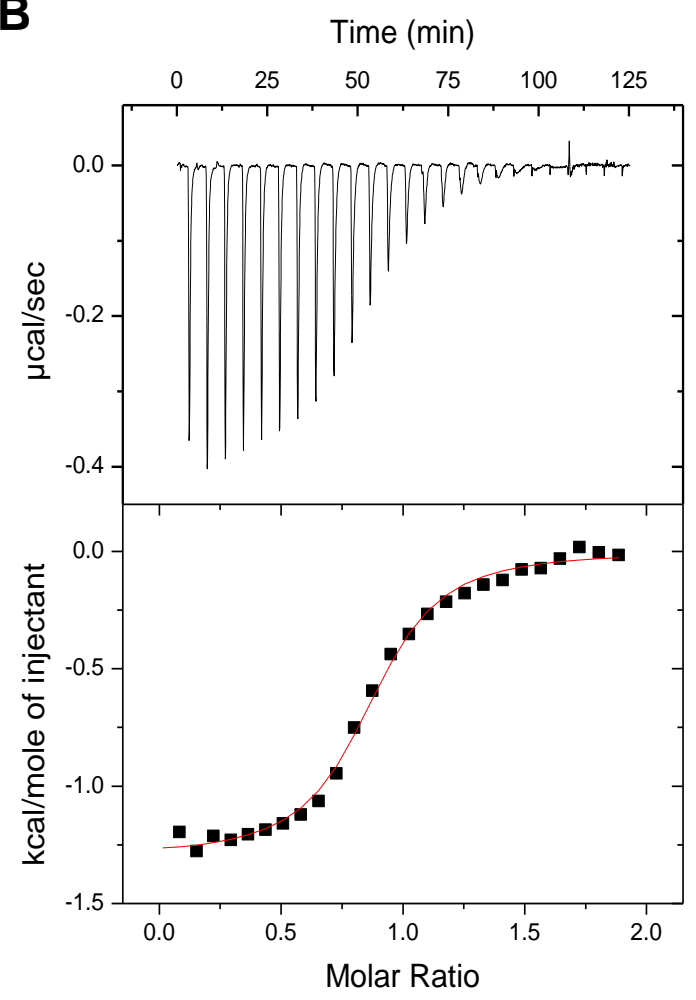

Figure S18. Representative thermogram of $1.0 \mathrm{mM} \mathrm{Cu}(\mathrm{II})$ titrated into A) $100 \mu \mathrm{M} \mathrm{N}$-term and B) $100 \mu \mathrm{M}$ C-term in $15 \mathrm{mM}$ MOPSO, $\mathrm{pH}$ 7.4. Red fit line for A) $\mathrm{n}=0.64 \pm 0.01 ; \mathrm{K}_{\mathrm{ITC}}=2.2( \pm 0.5)$ x $10^{6} ; \Delta \mathrm{HITC}=-1.34 \pm 0.02 \mathrm{kcal}$ mol- 1 , and B $) \mathrm{n}=0.860 \pm 0.009 ; \mathrm{K}_{\text {ITC }}=4.0( \pm 0.4) \times 10^{5} ; \Delta \mathrm{H}_{\text {ITC }}$ $=-1.30 \pm 0.02 \mathrm{kcal}$ mol- 1 . The average best fit data are summarized in Table S10. 
Table S1. Chemical shifts of assigned proton NMR resonances of apo WT C-peptide. Solutions were prepared at $1.5 \mathrm{mM}$ peptide in $95: 5(\mathrm{v} / \mathrm{v}) \mathrm{H}_{2} \mathrm{O}: \mathrm{D}_{2} \mathrm{O}$ with $10 \mathrm{mM}$ Tris- $\mathrm{d}_{11}$ at $\mathrm{pH} 7.4$ and spectra were collected at $800 \mathrm{MHz}$ and $10{ }^{\circ} \mathrm{C}$.

\begin{tabular}{|c|c|c|c|c|c|c|}
\hline \multicolumn{7}{|c|}{ Chemical Shifts of Assigned ${ }^{1} \mathrm{H}$ NMR Resonances of Apo C-peptide at pH 7.4 } \\
\hline \multirow[b]{2}{*}{ Residue } & \multicolumn{6}{|c|}{ Chemical Shifts at $10^{\circ} \mathrm{C}(\mathrm{ppm})$} \\
\hline & $\mathrm{NH}$ & $\mathrm{CHa}$ & $\mathrm{CH} \beta$ & $\mathrm{CH}$ & $\mathrm{CH \delta}$ & $\mathrm{NH}$ \\
\hline E1 & 8.04 & 4.34 & $1.84,2.04$ & 2.33 & - & - \\
\hline $\mathrm{A} 2$ & 8.38 & 4.32 & 1.37 & - & - & - \\
\hline E3 & 8.71 & 4.22 & $1.94,2.03$ & 2.28 & - & - \\
\hline D4 & 8.46 & 4.57 & $2.60,2.72$ & - & - & - \\
\hline L5 & 8.25 & 4.31 & 1.64 & 1.62 & $0.86,0.93$ & - \\
\hline Q6 & 8.56 & 4.25 & $1.98,2.04$ & 2.28 & - & $6.86,7.59$ \\
\hline V7 & 8.32 & 4.11 & 2.03 & 0.93 & - & - \\
\hline G8 & 8.62 & 3.97 & - & - & - & - \\
\hline Q9 & 8.33 & 4.36 & $2.00,2.09$ & 2.34 & - & $6.91,7.66$ \\
\hline V10 & 8.23 & 4.09 & 2.09 & $0.94,0.96$ & - & - \\
\hline E11 & 8.60 & 4.30 & $1.93,2.02$ & 2.25 & - & - \\
\hline L12 & 8.54 & 4.34 & 1.68 & 1.63 & $0.88,0.91$ & - \\
\hline G13 & 8.40 & 3.99 & - & - & - & - \\
\hline G14 & 8.39 & 3.83 & - & - & - & - \\
\hline G15 & 8.58 & 3.97 & - & - & - & - \\
\hline P16 & - & 4.40 & $1.90,2.29$ & 2.02 & 3.77 & - \\
\hline G17 & 8.32 & 3.81 & - & - & - & - \\
\hline A18 & 8.45 & 3.98 & 1.35 & - & - & - \\
\hline G19 & 8.48 & 3.98 & - & - & - & - \\
\hline $\mathrm{S} 20$ & 8.24 & 4.46 & 3.87 & & & \\
\hline L21 & 8.40 & 4.37 & 1.63 & 1.63 & $0.90,0.90$ & - \\
\hline Q22 & 8.41 & 4.60 & $1.93,2.09$ & 2.39 & - & $6.95,7.61$ \\
\hline P23 & - & 4.41 & $1.90,2.28$ & 2.03 & 3.66 & - \\
\hline L24 & 8.35 & 4.33 & 1.64 & 1.59 & $0.89,0.93$ & - \\
\hline A25 & 8.28 & 4.31 & 1.40 & - & - & - \\
\hline L26 & 8.43 & 4.28 & 1.64 & 1.58 & $0.90,0.93$ & - \\
\hline E27 & 8.48 & 4.33 & $2.00,2.12$ & 2.35 & - & - \\
\hline G28 & 8.67 & 3.95 & - & - & - & - \\
\hline S29 & 8.20 & 4.44 & 3.86 & - & - & - \\
\hline L30 & 8.45 & 4.40 & 1.66 & 1.65 & $0.90,0.90$ & - \\
\hline Q31 & 7.99 & 4.16 & $1.92,2.12$ & 2.28 & - & $6.92,7.66$ \\
\hline
\end{tabular}


Table S2. Chemical shifts of assigned proton NMR resonances of Zn(II)-bound WT C-peptide. Solutions were prepared at $1.5 \mathrm{mM}$ peptide in $95: 5(\mathrm{v} / \mathrm{v}) \mathrm{H}_{2} \mathrm{O}: \mathrm{D}_{2} \mathrm{O}$ with $10 \mathrm{mM}$ Tris- $\mathrm{d}_{11}$ at $\mathrm{pH} 7.4$ and spectra were collected at $800 \mathrm{MHz}$ and $10{ }^{\circ} \mathrm{C}$. Values in parentheses are a minor feature.

\begin{tabular}{|c|c|c|c|c|c|c|}
\hline \multicolumn{7}{|c|}{ Chemical Shifts of Assigned ${ }^{1} \mathrm{H}$ NMR Resonances of $\mathrm{Zn}(\mathrm{II}) / \mathrm{C}$-peptide at $\mathrm{pH} 7.4$} \\
\hline \multirow[b]{2}{*}{ Residue } & \multicolumn{6}{|c|}{ Chemical Shifts at $10^{\circ} \mathrm{C}(\mathrm{ppm})$} \\
\hline & $\mathrm{NH}$ & $\mathrm{CHa}$ & $\mathrm{CH} \beta$ & $\mathrm{CH} \gamma$ & $\mathrm{CH} \delta$ & $\mathrm{NHy}$ \\
\hline E1 & 8.04 & 4.34 & $1.84,2.04$ & 2.32 & - & - \\
\hline A2 & 8.38 & 4.31 & 1.36 & - & - & - \\
\hline E3 & 8.62 & 4.25 & $1.95,2.03$ & 2.27 & - & - \\
\hline D4 & $8.36(8.32)$ & $4.58(4.62)$ & $2.63,2.70(2.68)$ & - & - & - \\
\hline L5 & 8.18 & 4.31 & 1.64 & 1.60 & $0.85,0.91$ & \\
\hline Q6 & 8.56 & 4.25 & $1.98,2.04$ & 2.28 & - & $6.87,7.59$ \\
\hline V7 & 8.32 & 4.11 & 2.03 & 0.92 & - & - \\
\hline G8 & 8.61 & 3.97 & - & - & - & - \\
\hline Q9 & 8.31 & 4.36 & $2.00,2.09$ & 2.34 & - & $6.92,7.66$ \\
\hline V10 & 8.27 & 4.08 & 2.08 & 0.95 & - & - \\
\hline E11 & 8.66 & 4.30 & $1.92,2.01$ & 2.26 & - & - \\
\hline L12 & 8.55 & 4.34 & 1.67 & 1.63 & $0.86,0.91$ & - \\
\hline G13 & 8.40 & 3.98 & - & - & - & - \\
\hline G14 & 8.36 & 3.89 & - & - & - & - \\
\hline G15 & 8.58 & 3.97 & - & - & - & - \\
\hline P16 & - & 4.40 & $1.89,2.29$ & 2.01 & 3.78 & - \\
\hline G17 & 8.32 & 3.81 & - & - & - & - \\
\hline A18 & 8.44 & 3.98 & 1.36 & - & - & - \\
\hline G19 & 8.47 & 3.98 & - & - & - & - \\
\hline $\mathrm{S} 20$ & 8.24 & 4.45 & 3.88 & - & - & - \\
\hline L21 & 8.40 & 4.36 & 1.63 & 1.60 & $0.87,0.91$ & - \\
\hline Q22 & 8.41 & 4.61 & $1.92,2.09$ & 2.39 & - & $6.94,7.61$ \\
\hline P23 & - & 4.41 & $1.90,2.28$ & 2.02 & 3.66 & - \\
\hline L24 & 8.35 & 4.33 & 1.64 & 1.60 & $0.90,0.91$ & - \\
\hline A25 & 8.28 & 4.30 & 1.40 & - & - & - \\
\hline L26 & 8.42 & 4.28 & 1.64 & 1.60 & $0.89,0.93$ & - \\
\hline E27 & 8.49 & 4.35 & $1.98,2.11$ & 2.36 & - & - \\
\hline G28 & 8.65 & 3.95 & - & - & - & - \\
\hline S29 & 8.20 & 4.44 & 3.86 & - & - & - \\
\hline L30 & 8.45 & 4.39 & 1.67 & 1.64 & $0.89,0.92$ & - \\
\hline Q31 & 7.99 & 4.15 & $1.92,2.11$ & 2.28 & - & $6.92,7.64$ \\
\hline
\end{tabular}


Table S3. Chemical shifts of assigned proton NMR resonances of $\mathrm{Cu}(\mathrm{II})$-bound WT C-peptide. Solutions were prepared at $1.5 \mathrm{mM}$ peptide in $95: 5(\mathrm{v} / \mathrm{v}) \mathrm{H}_{2} \mathrm{O}: \mathrm{D}_{2} \mathrm{O}$ with $10 \mathrm{mM}$ Tris- $\mathrm{d}_{11}$ at $\mathrm{pH} 7.4$ and spectra were collected at $800 \mathrm{MHz}$ and $10{ }^{\circ} \mathrm{C} . \mathrm{obl}=$ obliterated signal; $\mathrm{sm}=$ reduced signal.

\begin{tabular}{|c|c|c|c|c|c|c|}
\hline \multicolumn{7}{|c|}{ Chemical Shifts of Assigned ${ }^{1} \mathrm{H}$ NMR Resonances of $\mathrm{Cu}(\mathrm{II}) / \mathrm{C}$-peptide at $\mathrm{pH} 7.4$} \\
\hline \multirow[b]{2}{*}{ Residue } & \multicolumn{6}{|c|}{ Chemical Shifts at $10^{\circ} \mathrm{C}(\mathrm{ppm})$} \\
\hline & $\mathrm{NH}$ & $\mathrm{CHa}$ & $\mathrm{CH} \beta$ & $\mathrm{CHy}$ & $\mathrm{CH} \delta$ & $\mathrm{NHy}$ \\
\hline E1 & 8.04 & 4.35 & $1.84,2.04$ & 2.32 & - & - \\
\hline A2 & 8.38 & 4.32 & $1.37(1.25,1.47 \mathrm{sm})$ & - & - & - \\
\hline E3 & 8.71 & 4.23 & obl & obl & - & - \\
\hline D4 & 8.46 & 4.59 & obl & - & - & - \\
\hline L5 & 8.25 & 4.32 & $1.64 \mathrm{sm}$ & $1.60 \mathrm{sm}$ & obl & - \\
\hline Q6 & 8.56 & 4.25 & $2.00,2.06$ & 2.28 & - & $6.88,7.59$ \\
\hline V7 & 8.32 & 4.11 & 2.03 & 0.92 & - & - \\
\hline G8 & 8.62 & 3.96 & - & - & - & - \\
\hline Q9 & 8.33 & 4.35 & $2.03,2.03$ & 2.34 & - & $6.92,7.66$ \\
\hline V10 & 8.23 & 4.10 & 2.09 & 0.95 & - & - \\
\hline E11 & 8.66 & 4.30 & $1.94,2.03 \mathrm{sm}$ & $2.26 \mathrm{sm}$ & - & - \\
\hline L12 & 8.54 & 4.35 & 1.68 & 1.62 & $0.87,0.92$ & - \\
\hline G13 & 8.40 & 3.98 & - & - & - & - \\
\hline G14 & 8.39 & 3.88 & - & - & - & - \\
\hline G15 & 8.58 & 3.98 & - & - & - & - \\
\hline P16 & - & 4.40 & $1.89,2.29$ & 2.02 & 3.78 & - \\
\hline G17 & 8.32 & 3.82 & - & - & - & - \\
\hline A18 & 8.45 & 3.98 & 1.35 & - & - & - \\
\hline G19 & 8.48 & 3.98 & - & - & - & - \\
\hline $\mathrm{S} 20$ & 8.24 & 4.45 & 3.88 & - & - & - \\
\hline L21 & 8.40 & 4.37 & 1.65 & 1.60 & $0.88,0.92$ & - \\
\hline Q22 & 8.41 & 4.60 & $1.93,2.09$ & 2.39 & - & $6.94,7.61$ \\
\hline P23 & - & 4.41 & $1.90,2.28$ & 2.02 & 3.66 & - \\
\hline L24 & 8.35 & 4.32 & 1.64 & 1.60 & $0.89,0.92$ & - \\
\hline A25 & 8.28 & 4.31 & 1.40 & - & - & - \\
\hline L26 & 8.42 & 4.28 & 1.65 & 1.61 & $0.91,0.93$ & - \\
\hline E27 & 8.49 & 4.34 & $2.00 \mathrm{sm}, 2.00 \mathrm{sm}$ & 2.37 & - & - \\
\hline G28 & 8.65 & 3.95 & - & - & - & - \\
\hline $\mathrm{S} 29$ & 8.21 & 4.44 & 3.87 & - & - & - \\
\hline L30 & 8.45 & 4.39 & 1.65 & 1.65 & $0.88,0.93$ & - \\
\hline Q31 & 7.99 & 4.16 & $1.92,2.12$ & 2.29 & - & $6.88,7.59$ \\
\hline
\end{tabular}


Table S4. $\Delta \delta$ of assigned proton NMR resonances of Zn(II)-bound WT C-peptide and apo WT Cpeptide. Solutions were prepared at $1.5 \mathrm{mM}$ peptide in 95:5 (v/v) $\mathrm{H}_{2} \mathrm{O}: \mathrm{D}_{2} \mathrm{O}$ with $10 \mathrm{mM}$ Tris- $\mathrm{d}_{11}$ at pH 7.4 and spectra were collected at $800 \mathrm{MHz}$ and $10{ }^{\circ} \mathrm{C}$. Visual representations shown in Figures S4 and S5. Values in parentheses are a minor feature.

\begin{tabular}{|c|c|c|c|c|c|c|}
\hline \multicolumn{7}{|c|}{$\Delta \delta$ of the Assigned ${ }^{1} \mathrm{H}$ NMR Resonances of $\mathrm{Zn}(\mathrm{II}) / \mathrm{C}$-peptide at $\mathrm{pH} 7.4$} \\
\hline \multirow[b]{2}{*}{ Residue } & \multicolumn{6}{|c|}{$\Delta \delta=\delta(\mathrm{Zn}(\mathrm{II}) / \mathrm{C}$-peptide $)-\delta($ apo C-peptide $)$ at $10^{\circ} \mathrm{C}(\mathrm{ppm})$} \\
\hline & $\mathrm{NH}$ & $\mathrm{CHa}$ & $\mathrm{CH} \beta$ & $\mathrm{CHY}$ & $\mathrm{CH} \delta$ & $\mathrm{NHY}$ \\
\hline E1 & 0.00 & 0.00 & $0.00,0.00$ & -0.01 & & \\
\hline $\mathrm{A} 2$ & 0.00 & -0.01 & -0.01 & & & \\
\hline E3 & -0.09 & 0.03 & $0.01,0.00$ & -0.01 & & \\
\hline D4 & $-0.10(-0.14)$ & $0.01(0.05)$ & $0.03,-0.02(0.08,-0.02)$ & & & \\
\hline L5 & -0.07 & 0.00 & 0.00 & -0.02 & $-0.01,-0.02$ & \\
\hline Q6 & 0.00 & 0.00 & $0.00,0.00$ & 0.00 & & $0.01,0.00$ \\
\hline V7 & 0.00 & 0.00 & 0.00 & $-0.01,-0.01$ & & \\
\hline G8 & -0.01 & 0.00 & & & & \\
\hline Q9 & -0.02 & 0.00 & $0.00,0.00$ & 0.00 & & $0.01,0.00$ \\
\hline V10 & 0.04 & -0.01 & -0.01 & $0.01,-0.01$ & & \\
\hline E11 & 0.06 & 0.00 & $-0.01,-0.01$ & 0.01 & & \\
\hline L12 & 0.01 & 0.00 & -0.01 & 0.00 & $-0.02,0.00$ & \\
\hline G13 & 0.00 & -0.01 & & & & \\
\hline G14* & -0.03 & 0.06 & & & & \\
\hline G15* & 0.00 & 0.00 & & & & \\
\hline P16 & & 0.00 & $-0.01,0.00$ & -0.01 & 0.01 & \\
\hline G17 & 0.00 & 0.00 & & & & \\
\hline A18 & -0.01 & 0.00 & 0.01 & & & \\
\hline G19 & -0.01 & 0.00 & & & & \\
\hline $\mathrm{S} 20$ & 0.00 & -0.01 & 0.01 & & & \\
\hline L21 & 0.00 & -0.01 & 0.00 & -0.03 & $-0.03,0.01$ & \\
\hline Q22 & 0.00 & 0.01 & $-0.01,0.00$ & 0.00 & & $-0.01,0.00$ \\
\hline P23 & & 0.00 & $0.00,0.00$ & -0.01 & 0.00 & \\
\hline L24 & 0.00 & 0.00 & 0.00 & 0.01 & $0.01,-0.02$ & \\
\hline A25 & 0.00 & -0.01 & 0.00 & & & \\
\hline L26 & -0.01 & 0.00 & 0.00 & 0.02 & $-0.01,0.00$ & \\
\hline E27 & 0.01 & 0.02 & $-0.02,-0.01$ & 0.01 & & \\
\hline G28 & -0.02 & 0.00 & & & & \\
\hline $\mathrm{S} 29$ & 0.00 & 0.00 & 0.00 & & & \\
\hline L30 & 0.00 & -0.01 & 0.01 & -0.01 & $-0.01,0.02$ & \\
\hline Q31 & 0.00 & -0.01 & $0.00,0.01$ & 0.00 & & $0.00,-0.02$ \\
\hline
\end{tabular}


Table S5. $\Delta \delta$ of assigned proton NMR resonances of $\mathrm{Cu}(\mathrm{II})$-bound WT C-peptide and apo WT Cpeptide. Solutions were prepared at $1.5 \mathrm{mM}$ peptide in 95:5 (v/v) $\mathrm{H}_{2} \mathrm{O}: \mathrm{D}_{2} \mathrm{O}$ with $10 \mathrm{mM}$ Tris- $\mathrm{d}_{11}$ at pH 7.4 and spectra were collected at $800 \mathrm{MHz}$ and $10{ }^{\circ} \mathrm{C}$. Visual representations shown in Figures $\mathrm{S} 4$ and $\mathrm{S} 5 . \mathrm{obl}=$ obliterated signal; $\mathrm{sm}=$ reduced signal.

\begin{tabular}{|c|c|c|c|c|c|c|}
\hline \multicolumn{7}{|c|}{$\Delta \delta$ of the Assigned ${ }^{1} \mathrm{H}$ NMR Resonances of $\mathrm{Cu}(\mathrm{II}) / \mathrm{C}$-peptide at $\mathrm{pH} 7.4$} \\
\hline \multirow[b]{2}{*}{ Residue } & \multicolumn{6}{|c|}{$\Delta \delta=\delta(\mathrm{Cu}(\mathrm{II}) / \mathrm{C}$-peptide $)-\delta($ apo $\mathrm{C}$-peptide $)$ at $10^{\circ} \mathrm{C}(\mathrm{ppm})$} \\
\hline & $\mathrm{NH}$ & $\mathrm{CHa}$ & $\mathrm{CH} \beta$ & $\mathrm{CH}$ & $\mathrm{CH} \delta$ & $\mathrm{NHy}$ \\
\hline E1 & 0.00 & 0.01 & $0.00,0.00$ & -0.01 & & \\
\hline A2 & 0.00 & 0.00 & $0.00(-0.12 \mathrm{sm}, 0.10 \mathrm{sm})$ & & & \\
\hline E3 & 0.00 & 0.01 & obl & obl & & \\
\hline D4 & 0.00 & 0.02 & obl & & & \\
\hline L5 & 0.00 & 0.01 & $0.00 \mathrm{sm}$ & $-0.04 \mathrm{sm}$ & obl & \\
\hline Q6 & 0.00 & 0.00 & $0.02,0.02$ & 0.00 & & $0.02,0.00$ \\
\hline V7 & 0.00 & 0.00 & 0.00 & $-0.01,-0.01$ & & \\
\hline G8 & 0.00 & -0.01 & & & & \\
\hline Q9 & 0.00 & -0.01 & $0.03,-0.06$ & 0.00 & & $0.01,0.00$ \\
\hline V10 & 0.00 & 0.01 & 0.00 & $0.01,-0.01$ & & \\
\hline E11 & 0.06 & 0.00 & $0.01,0.01 \mathrm{sm}$ & $0.01 \mathrm{sm}$ & & \\
\hline L12 & 0.00 & 0.01 & 0.00 & -0.01 & $-0.01,-0.01$ & \\
\hline G13 & 0.00 & -0.01 & & & & \\
\hline G14* & 0.00 & 0.05 & & & & \\
\hline G15* & 0.00 & 0.01 & & & & \\
\hline P16 & & 0.00 & $-0.01,0.00$ & 0.00 & 0.01 & \\
\hline G17 & 0.00 & 0.01 & & & & \\
\hline A18 & 0.00 & 0.00 & 0.00 & & & \\
\hline G19 & 0.00 & 0.00 & & & & \\
\hline $\mathrm{S} 20$ & 0.00 & -0.01 & 0.01 & & & \\
\hline L21 & 0.00 & 0.00 & 0.02 & -0.03 & $-0.02,0.02$ & \\
\hline Q22 & 0.00 & 0.00 & $0.00,0.00$ & 0.00 & & $-0.01,0.00$ \\
\hline P23 & & 0.00 & $0.00,0.00$ & -0.01 & 0.00 & \\
\hline L24 & 0.00 & -0.01 & 0.00 & 0.01 & $0.00,-0.01$ & \\
\hline A25 & 0.00 & 0.00 & 0.00 & & & \\
\hline L26 & -0.01 & 0.00 & 0.01 & 0.03 & $0.01,0.00$ & \\
\hline E27 & 0.01 & 0.01 & $0.00 \mathrm{sm}, 0.00 \mathrm{sm}$ & 0.02 & & \\
\hline G28 & -0.02 & 0.00 & & & & \\
\hline S29 & 0.01 & 0.00 & 0.01 & & & \\
\hline L30 & 0.00 & -0.01 & -0.01 & 0.00 & $-0.02,0.03$ & \\
\hline Q31 & 0.00 & 0.00 & $0.00,0.00$ & 0.01 & & $-0.04,-0.07$ \\
\hline
\end{tabular}


Table S6. Experimental fit parameters from at least three titrations in each buffer.

\begin{tabular}{cccc}
\hline Buffer & $\mathbf{n}_{\mathrm{ITC}}$ & $\mathbf{K}_{\mathrm{ITC}}$ & $\left.\Delta \mathbf{H}_{\mathrm{ITC}}(\mathbf{k c a l ~ m o l})^{-1}\right)$ \\
\hline MOPS & $0.8 \pm 0.2$ & $2( \pm 1) \times 10^{6}$ & $-1.3 \pm 0.2$ \\
MOPSO & $1.0 \pm 0.1$ & $5( \pm 2) \times 10^{5}$ & $-1.31 \pm 0.03$ \\
\hline
\end{tabular}


Table S7. Chemical shifts of assigned proton NMR resonances of apo E3A D4A C-peptide. Solutions were prepared at $1.5 \mathrm{mM}$ peptide in 95:5 (v/v) $\mathrm{H}_{2} \mathrm{O}: \mathrm{D}_{2} \mathrm{O}$ with $10 \mathrm{mM}$ Tris- $\mathrm{d}_{11}$ at $\mathrm{pH} 7.4$ and spectra were collected at $800 \mathrm{MHz}$ and $10{ }^{\circ} \mathrm{C}$.

\begin{tabular}{|c|c|c|c|c|c|c|}
\hline \multicolumn{7}{|c|}{ Chemical Shifts of Assigned ${ }^{1} \mathrm{H}$ NMR Resonances of Apo E3A D4A C-peptide at pH 7.4} \\
\hline \multirow[b]{2}{*}{ Residue } & \multicolumn{6}{|c|}{ Chemical Shifts at $10^{\circ} \mathrm{C}(\mathrm{ppm})$} \\
\hline & $\mathrm{NH}$ & $\mathrm{CHa}$ & $\mathrm{CH} \beta$ & $\mathrm{CHy}$ & $\mathrm{CH} \delta$ & $\mathrm{NHY}$ \\
\hline E1 & 8.04 & 4.34 & $1.84,2.03$ & 2.31 & - & - \\
\hline A2 & 8.44 & 4.31 & 1.38 & - & - & - \\
\hline A3 & 8.40 & 4.28 & 1.37 & - & - & - \\
\hline A4 & 8.37 & 4.31 & 1.36 & - & - & - \\
\hline L5 & 8.30 & 4.31 & 1.62 & 1.56 & $0.89,0.92$ & - \\
\hline Q6 & 8.56 & 4.25 & $1.98,2.04$ & 2.28 & - & $6.87,7.59$ \\
\hline V7 & 8.31 & 4.12 & 2.05 & 0.92 & - & - \\
\hline G8 & 8.66 & 3.96 & - & - & - & - \\
\hline Q9 & 8.32 & 4.36 & $2.00,2.09$ & 2.34 & - & $6.92,7.67$ \\
\hline V10 & 8.35 & 4.09 & 2.06 & $0.94,0.94$ & - & - \\
\hline E11 & 8.66 & 4.30 & $1.94,2.04$ & 2.25 & - & - \\
\hline L12 & 8.54 & 4.34 & 1.67 & 1.61 & $0.88,0.92$ & - \\
\hline G13 & n.d. & n.d. & - & - & - & - \\
\hline G14 & n.d. & n.d. & - & - & - & - \\
\hline G15 & n.d. & n.d. & - & - & - & - \\
\hline P16 & - & n.d. & n.d. & n.d. & n.d. & - \\
\hline G17 & 8.39 & 3.98 & - & - & - & - \\
\hline A18 & 8.54 & 4.25 & 1.37 & - & - & - \\
\hline G19 & 8.58 & 3.97 & - & - & - & - \\
\hline $\mathrm{S} 20$ & 8.24 & 4.45 & 3.87 & - & - & - \\
\hline L21 & 8.40 & 4.37 & 1.63 & 1.61 & $0.88,0.93$ & - \\
\hline Q22 & 8.41 & 4.61 & $1.93,2.09$ & 2.39 & - & $6.94,7.61$ \\
\hline P23 & - & 4.61 & $1.92,2.39$ & 2.09 & $3.65,3.77$ & - \\
\hline L24 & 8.35 & 4.32 & 1.63 & 1.58 & $0.95,0.95$ & - \\
\hline A25 & 8.27 & 4.30 & 1.40 & - & - & - \\
\hline L26 & 8.42 & 4.28 & 1.63 & 1.58 & $0.91,0.93$ & - \\
\hline E27 & 8.47 & 4.37 & $1.97,2.09$ & 2.35 & - & - \\
\hline G28 & 8.61 & 3.98 & - & - & - & - \\
\hline S29 & 8.20 & 4.44 & 3.86 & - & - & - \\
\hline L30 & 8.45 & 4.38 & 1.66 & 1.66 & $0.88,0.93$ & - \\
\hline Q31 & 7.99 & 4.15 & $1.9,2.11$ & 2.28 & - & $6.87,7.59$ \\
\hline
\end{tabular}


Table S8. Chemical shifts of assigned proton NMR resonances of $\mathrm{Cu}(\mathrm{II})$-bound E3A D4A Cpeptide. Solutions were prepared at $1.5 \mathrm{mM}$ peptide in $95: 5(\mathrm{v} / \mathrm{v}) \mathrm{H}_{2} \mathrm{O}: \mathrm{D}_{2} \mathrm{O}$ with $10 \mathrm{mM}$ Tris-d $\mathrm{d}_{11}$ at $\mathrm{pH} 7.4$ and spectra were collected at $800 \mathrm{MHz}$ and $10^{\circ} \mathrm{C}$.

\begin{tabular}{|c|c|c|c|c|c|c|}
\hline \multicolumn{7}{|c|}{ Chemical Shifts of Assigned ${ }^{1} \mathrm{H}$ NMR Resonances of $\mathrm{Cu}(\mathrm{II}) / \mathrm{E} 3 \mathrm{~A}$ D4A C-peptide at $\mathrm{pH} 7.4$} \\
\hline \multirow[b]{2}{*}{ Residue } & \multicolumn{6}{|c|}{ Chemical Shifts at $10^{\circ} \mathrm{C}(\mathrm{ppm})$} \\
\hline & $\mathrm{NH}$ & $\mathrm{CHa}$ & $\mathrm{CH} \beta$ & $\mathrm{CH}$ & $\mathrm{CH} \delta$ & $\mathrm{NHy}$ \\
\hline E1 & 8.05 & 4.34 & $1.84,2.04$ & 2.32 & - & - \\
\hline $\mathrm{A} 2$ & 8.45 & 4.30 & 1.35 & - & - & - \\
\hline A3 & 8.40 & 4.27 & 1.37 & - & - & - \\
\hline A4 & 8.37 & 4.31 & 1.37 & - & - & - \\
\hline L5 & 8.27 & 4.31 & 1.63 & 1.56 & $0.92,0.92$ & - \\
\hline Q6 & 8.56 & 4.25 & $2.00,2.05$ & 2.29 & - & n.d. \\
\hline V7 & 8.32 & 4.12 & 2.05 & 0.92 & - & - \\
\hline G8 & 8.67 & 3.96 & - & - & - & - \\
\hline Q9 & 8.30 and 8.32 & 4.35 & $2.00,2.09$ & 2.34 & - & n.d. \\
\hline V10 & 8.34 & 4.10 & 2.05 & 0.92 & - & - \\
\hline E11 & 8.66 & 4.30 & $1.94,2.03$ & 2.28 & - & - \\
\hline L12 & 8.54 & 4.34 & 1.67 & 1.61 & $0.90,0.90$ & - \\
\hline G13 & n.d. & n.d. & - & - & - & - \\
\hline G14 & n.d. & n.d. & - & - & - & - \\
\hline G15 & n.d. & n.d. & - & - & - & - \\
\hline P16 & - & n.d. & n.d. & n.d. & n.d. & - \\
\hline G17 & 8.40 & 3.98 & - & - & - & - \\
\hline A18 & 8.50 & 4.37 & 1.38 & - & - & - \\
\hline G19 & 8.56 & 3.97 & - & - & - & - \\
\hline S20 & 8.24 & 4.45 & 3.87 & - & - & - \\
\hline L21 & 8.40 & 4.37 & 1.62 & 1.62 & $0.89,0.94$ & - \\
\hline Q22 & 8.41 & 4.60 & $1.94,2.09$ & 2.39 & - & $6.94,7.61$ \\
\hline P23 & - & n.d. & n.d. & n.d. & n.d. & - \\
\hline L24 & 8.35 & 4.32 & 1.62 & 1.62 & $0.93,0.93$ & - \\
\hline A25 & 8.27 & 4.31 & 1.41 & - & - & - \\
\hline L26 & 8.42 & 4.28 & 1.64 & 1.58 & 0.91 .0 .94 & - \\
\hline E27 & 8.48 & 4.38 & $1.97,2.09$ & 2.37 & - & - \\
\hline G28 & 8.59 & 3.97 & - & - & - & - \\
\hline S29 & 8.20 & 4.44 & 3.87 & - & - & - \\
\hline L30 & 8.45 & 4.40 & 1.66 & 1.66 & $0.89,0.93$ & - \\
\hline Q31 & 7.99 & 4.15 & $1.92,2.13$ & 2.28 & - & n.d. \\
\hline
\end{tabular}


Table S9. $\Delta \delta$ of assigned proton NMR resonances of $\mathrm{Cu}(\mathrm{II})$-bound E3A D4A C-peptide and apo E3A D4A C-peptide. Solutions were prepared at $1.5 \mathrm{mM}$ peptide in $95: 5(\mathrm{v} / \mathrm{v}) \mathrm{H}_{2} \mathrm{O}: \mathrm{D}_{2} \mathrm{O}$ with 10 $\mathrm{mM}$ Tris- $\mathrm{d}_{11}$ at $\mathrm{pH} 7.4$ and spectra were collected at $800 \mathrm{MHz}$ and $10^{\circ} \mathrm{C}$. Visual representations shown in Figures S11 and S12.

\begin{tabular}{|c|c|c|c|c|c|c|}
\hline \multicolumn{7}{|c|}{$\Delta \delta$ of the Assigned ${ }^{1} \mathrm{H}$ NMR Resonances of $\mathrm{Cu}(\mathrm{II}) / \mathrm{E} 3 \mathrm{~A}$ D4A C-peptide at $\mathrm{pH} 7.4$} \\
\hline \multirow[b]{2}{*}{ Residue } & \multicolumn{6}{|c|}{$\Delta \delta=\delta(\mathrm{Cu}(\mathrm{II}) / \mathrm{C}$-peptide $)-\delta($ apo C-peptide $)$ at $10^{\circ} \mathrm{C}(\mathrm{ppm})$} \\
\hline & $\mathrm{NH}$ & $\mathrm{CHa}$ & $\mathrm{CH} \beta$ & $\mathrm{CHy}$ & $\mathrm{CH} \delta$ & $\mathrm{NHY}$ \\
\hline E1 & 0.01 & 0.00 & $0.00,0.01$ & 0.01 & - & - \\
\hline $\mathrm{A} 2$ & 0.01 & -0.01 & -0.03 & - & - & - \\
\hline A3 & 0.00 & -0.01 & 0.00 & - & - & - \\
\hline A4 & 0.00 & 0.00 & 0.01 & - & - & - \\
\hline L5 & -0.03 & 0.00 & 0.01 & 0.00 & $0.03,0.00$ & - \\
\hline Q6 & 0.00 & 0.00 & $0.02,0.01$ & 0.01 & - & n.d. \\
\hline V7 & 0.01 & 0.00 & 0.00 & 0.00 & - & - \\
\hline G8 & 0.01 & 0.00 & - & - & - & - \\
\hline Q9 & -0.02 and 0.00 & -0.01 & $0.00,0.00$ & 0.00 & - & n.d. \\
\hline V10 & -0.01 & 0.01 & -0.01 & $-0.02,-0.02$ & - & - \\
\hline E11 & 0.00 & 0.00 & $0.00,-0.01$ & 0.03 & - & - \\
\hline L12 & 0.00 & 0.00 & 0.00 & 0.00 & $0.02,-0.02$ & - \\
\hline G13 & n.d. & n.d. & - & - & - & - \\
\hline G14 & n.d. & n.d. & - & - & - & - \\
\hline G15 & n.d. & n.d. & - & - & - & - \\
\hline P16 & - & n.d. & n.d. & n.d. & n.d. & - \\
\hline G17 & 0.01 & 0.00 & - & - & - & - \\
\hline A18 & -0.04 & 0.12 & 0.01 & - & - & - \\
\hline G19 & -0.02 & 0.00 & - & - & - & - \\
\hline $\mathrm{S} 20$ & 0.00 & 0.00 & 0.00 & - & - & - \\
\hline L21 & 0.00 & 0.00 & -0.01 & 0.01 & $0.01,0.01$ & - \\
\hline Q22 & 0.00 & -0.01 & $0.01,0.00$ & 0.00 & - & $0.00,0.00$ \\
\hline P23 & - & n.d. & n.d. & n.d. & n.d. & - \\
\hline L24 & 0.00 & 0.00 & -0.01 & 0.04 & $-0.02,-0.02$ & - \\
\hline A25 & 0.00 & 0.01 & 0.01 & - & - & - \\
\hline L26 & 0.00 & 0.00 & 0.01 & 0.00 & $0.00,0.01$ & - \\
\hline E27 & 0.01 & 0.01 & $0.00,0.00$ & 0.02 & - & - \\
\hline G28 & -0.02 & -0.01 & - & - & - & - \\
\hline S29 & 0.00 & 0.00 & 0.01 & - & - & - \\
\hline L30 & 0.00 & 0.02 & 0.00 & 0.00 & $0.01,0.00$ & - \\
\hline Q31 & 0.00 & 0.00 & $0.02,0.02$ & 0.00 & - & n.d. \\
\hline
\end{tabular}


Table S10. ITC experimental fit parameters from $1.0 \mathrm{mM} \mathrm{Cu}$ (II) titrated into $100 \mu \mathrm{M}$ peptide in $15 \mathrm{mM}$ buffer, $\mathrm{pH} 7.4$ at $25{ }^{\circ} \mathrm{C}$. Titrations were in triplicate for all WT C-peptide, N-term, and C-term, and in duplicate for E3A/D4A C-peptide. The data show that E3A/D4A C-peptide has a smaller $\mathrm{n}_{\text {ITC }}$ indicating 1:2 $\mathrm{Cu}(\mathrm{II})$ :peptide stoichiometry and that $\mathrm{C}$-term has a smaller $\mathrm{K}_{\text {ITC }}$ than the other peptides.

\begin{tabular}{|c|c|c|c|c|c|c|}
\hline Variant & Buffer & nITC & $\mathbf{K}_{\text {ITC }}$ & $\begin{array}{c}\Delta \mathrm{HITC}_{\mathrm{ITC}} \\
\left(\mathrm{kcal} \mathrm{mol}^{-1}\right) \\
\end{array}$ & $\mathbf{K}_{\mathbf{C u}(\mathrm{II}) / \mathrm{C} \text {-peptide }}$ & $\begin{array}{c}\Delta \mathrm{HCu}_{\mathrm{CII}) / \mathrm{C} \text {-peptide }} \\
\left(\mathrm{kcal} \mathrm{mol}^{-1}\right) \\
\end{array}$ \\
\hline \multirow[t]{2}{*}{ WT } & MOPS & $0.8 \pm 0.2$ & $2( \pm 1) \times 10^{6}$ & $-1.3 \pm 0.2$ & $2( \pm 1) \times 10^{8}$ & $-2 \pm 1$ \\
\hline & MOPSO & $1.0 \pm 0.1$ & $5( \pm 2) \times 10^{5}$ & $-1.31 \pm 0.03$ & $6( \pm 3) \times 10^{7}$ & $-2 \pm 1$ \\
\hline \multirow[t]{2}{*}{ E3A/D4A } & MOPS & $0.5 \pm 0.2$ & $1( \pm 0.6) \times 10^{6}$ & $-1.8 \pm 0.2$ & $9( \pm 6) \times 10^{7}$ & $-3 \pm 1$ \\
\hline & MOPSO & $0.55 \pm 0.07$ & $4( \pm 1) \times 10^{5}$ & $-1.80 \pm 0.09$ & $4( \pm 1) \times 10^{7}$ & $-2.8 \pm 0.8$ \\
\hline N-term & MOPS & $0.6 \pm 0.2$ & $2.0( \pm 0.7) \times 10^{6}$ & $-1.1 \pm 0.4$ & n.d. & n.d. \\
\hline C-term & MOPS & $0.7 \pm 0.1$ & $3( \pm 1) \times 10^{5}$ & $-1.28 \pm 0.06$ & n.d. & n.d. \\
\hline
\end{tabular}




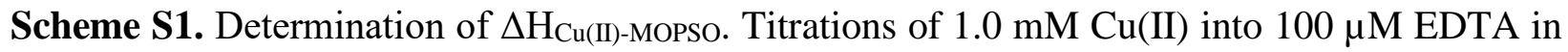
$15 \mathrm{mM}$ MOPSO, $\mathrm{pH} 7.4$ with fit parameters from three experiments: $\mathrm{n}_{\text {ITC }}=0.91 \pm 0.09 ; \mathrm{K}_{\mathrm{ITC}}=4$ $( \pm 1) \times 10^{7} ; \Delta \mathrm{H}_{\text {ITC }}=-7.5 \pm 0.9 \mathrm{kcal} \mathrm{mol}^{-1} . \Delta \mathrm{H}_{\mathrm{Cu}(\mathrm{II}) \text {-MOPSO }}$ is found to be $-1.4 \mathrm{kcal} \mathrm{mol}^{-1}$. All $\Delta \mathrm{H}$ values are found in NIST. ${ }^{3}$ All competing equilibria are accounted for as described by Grossoehme et al. ${ }^{1}$

\section{Equlibria}

$\mathrm{Cu}(\mathrm{II})-\mathrm{MOPSO} \rightarrow \mathrm{Cu}(\mathrm{II})+\mathrm{MOPSO}$

EDTA-2 $\mathrm{H}^{+} \rightarrow \mathrm{EDTA}^{+} \mathrm{H}^{+}+\mathrm{H}^{+}$

$\mathrm{EDTA}-\mathrm{H}^{+} \rightarrow \mathrm{EDTA}+\mathrm{H}^{+}$

$\mathrm{MOPSO}+\mathrm{H}^{+} \rightarrow \mathrm{MOPSO}-\mathrm{H}^{+}$

$\mathrm{Cu}(\mathrm{II})+\mathrm{EDTA} \rightarrow \mathrm{Cu}(\mathrm{II})-\mathrm{EDTA}$

\begin{tabular}{cc}
$\mathbf{n}$ & $\boldsymbol{\Delta} \mathbf{H}\left(\mathrm{kcal} \mathrm{mol}^{-1}\right)$ \\
1 & $-\mathrm{X}$ \\
0.05 & 4.2 \\
0.99 & 5.6 \\
1.04 & -6.19 \\
1 & -8.2 \\
\hline
\end{tabular}

$\mathbf{n} \times \Delta \mathbf{H}\left(\mathbf{k c a l ~ m o l}^{-1}\right)$
$-\mathrm{X}$
0.2142
5.544
-6.4376
-8.2
$\Delta \mathrm{H}_{\mathrm{ITC}}=-\mathrm{X}-8.8794$
$\mathrm{X}=-\Delta \mathrm{H}_{\mathrm{ITC}}-8.8794$
$\mathrm{X}=\Delta \mathrm{H}_{\mathrm{Cu}(\mathrm{II})-\mathrm{MOPSO}}=-1.364$




\section{$\underline{\text { References }}$}

(1) Grossoehme, N. E.; Spuches, A. M.; Wilcox, D. E. Application of Isothermal Titration Calorimetry in Bioinorganic Chemistry. J. Biol. Inorg. Chem. 2010, 15 (8), 1183-1191. https://doi.org/10.1007/s00775-010-0693-3.

(2) Peisach, J.; Blumberg, W. E. Structural Implications Derived from the Analysis of Electron Paramagnetic Resonance Spectra of Natural and Artificial Copper Proteins. Arch. Biochem. Biophys. 1974, 165 (2), 691-708. https://doi.org/Doi: 10.1016/00039861(74)90298-7.

(3) NIST Critically Selected Stability Constants of Metal Complexes, Version 8.0. 